\title{
JUDICIAL ATTITUDES AND VOTING BEHAVIOR: THE I96I TERM OF THE UNITED STATES SUPREME COURT
}

\author{
Glendon SchuberT*
}

I

Legal Realism: From Art to Science

Lawyers, political scientists, and other social scientists share an interest in seeking to understand how complex social relationships and patterns of human interaction can be studied so as to increase our stockpile of social knowledge about law and the policy-making processes through which it is formulated. They are not agreed, however, as to how this goal best may be realized.

Recollection of the major emphases of legal realism may be instructive in providing perspective for dispassionate appraisal of contemporary proposals on behalf of a science of judicial behavior. For Holmes, realism was a temper, the mood of pragmatism; ; $^{1}$ while for Llewellyn, realism was only a method, and the "method" was to get at the real facts and issues that underlie legal controversies and the procedures employed to resolve them. ${ }^{2}$ For Cardozo, realism meant to understand the values of the judge, since the judge's personality was the only funnel through which policy norms could enter into judicial decisions. ${ }^{3}$ Frank, who was more influenced by Freudian psychology, shifted the focus to the sets of unique life experiences of judges which shaped their individual value-patterns; ${ }^{4}$ Felix Cohen offered the complementary view that the decisions of individual judges, whatever might be the forces that shaped their individual value-patterns, acquired social significance only when evaluated in the context of complex antecedent and consequent processes involving the interaction of many humans besides the judge. 5 There were, of course, other well-known legal realists; but our present sample exemplifies the major emphases which realism brought to the study of American law:

What are the real events that underlie the policy choices urged upon judges?

How does the interaction of other persons limit the range of judicial choice?

What do judges believe, and why?

* A.B. 1940, Ph.D. 1948, Syracuse University. Professor of Political Science, Michigan State University. Fellow, Center for Advanced Study in the Behavioral Sciences, 1960-61. Author, Tye Puncro Interest (1961), Constitutional Politics (1960), Qunntitative Analsysis of Judiciat Bemavior (1959), The Prestdency in the Courts (1957); editor, Judicial Decision-Maring (ig63). Contributor to periodicals in the fields of political science, law, and behavioral science.

${ }^{2}$ Holmes, The Path of the Law, io HARv. L. REv. 457 (1897).

2 Kari N. Llewellyn, The Common Law Tradition-Deciding Appeals 5 ro (1960); and also Llewellyn, Some Realism About Realism, 44 HArv. L. Rev. I222 (I931).

${ }^{3}$ Benjaumn N. Cardozo, The Nature of the Judicial. Process (1927).

- Jerome Frank, Law and the Modern Mind (1930).

Cohen, Transcendental Nonsense and the Functional Approach, 35 CoLvs. L. REv. 843,847 (1935). 
What are the practical consequences entailed by judicial preference of one policy alternative over another?

One thing that all of these questions have in common is that they direct attention away from the manifest content of judicial opinions, and away from a concern for logical consistency among sets of legal norms. A knowledge of what judges do and say is important, but it is by no means enough; a realistic understanding of judicial decision-making demands that the acts of judges be examined like any other forms of social behavior. The long-standing ties that bind the study of law to the philosophical and historical traditions remain; but they are being augmented by new bridges across interdisciplinary chasms, and more recent links have been forged with sociology, economics, psychology, political science, social psychology, and even with anthropology. ${ }^{6}$ Each of these sister disciplines has made somethough differential-progress along the long road that connects art with science. Despite the verbalisms about "legal science," one need only contrast this issue of this journal with the current issue of any of a hundred other law journals, in order to perceive the extent to which legal study remains the handmaiden to metaphors that now belong to the ages. ${ }^{7}$ Even better, contrast the average legal journal with any of the dozen journals published by the American Psychological Association: it is not the difference in content; it is the difference in ethos that is significant.

The primary thrust of legal realism was in the direction of reorienting legal study in the spirit of the modern temper, and to redefine its role as that of an applied social science. Just as the profession of medicine had come, earlier in this century, to assume the status of an applied science, dependent upon the theoretical and empirical research done by physicists, chemists, biologists, biochemists, biophysicists, and so on, so has medical science increasingly come to depend also upon the work of social scientists such as psychologists, sociologists, economists, and even political scientists. The legal science of the future doubtless will depend much less than medical science upon basic research in the natural sciences, and much more upon the other social sciences; but its concern increasingly will be not with words in books but rather with the behavior of people. We are all familiar with the harbingers of change; our differences lie in the degrees of optimism and pessimism with which we anticipate the impact of the revolution in the behavioral sciences upon the study and practice of law. ${ }^{8}$

\footnotetext{
- Kari N. Lleweliyn \& E. Adamson Hoeber, The Cheyenne Way (1941); and cf. Karl N. Llewellyn, The Common LAW Tradition-Decidino Appenls 513, 520 (1960): "The law of the Cheyenne Indians made clear to me what I had never before dreamed: to wit, that law and justice had no need at all to be in conflict or even in too much tension.... And it was on this foundation of experience with Cheyenne law that I became able to spot and understand the Grand Style as I met it in the early work of our own courts.... [N] othing germinated until after [my] meeting [with] the Cheyennes."

${ }^{-}$Landau, On the Use of Metaphor in Political Analysis, 28 Soctar Research 33I (I96r).

-Truman, The Impact on Political Science of the Revolution in the Behavioral Sciences, in Research Frontiers in Politics and Government: Brookings Lectures, 1955, at 202 (1955); Eulau, Segments of Political Science Most Susceptible to Behavioristic Treatment, in James C. Charsesworth (Ed.), The Limits of Behuvioralism in Political Science 26 (1962).
} 


\section{II}

\section{Prediction in Law and Judicial Behavior}

\section{A. Why Is Prediction Important?}

"The prophecies of what the courts will do in fact and nothing more pretentious," said Holmes, "are what I mean by law." This iconoclasm of three generations ago now has achieved the status of orthodoxy. The model of the laboratory and its associated experimental method has pervaded our cultural understanding; we now are prepared to assume that the power of any science lies in its capacity to make successful predictions concerning the behavior of the particles that constitute its data.

When we focus our attention upon the behavior of judges, the ultimate test of our theory and methods lies in our ability correctly to predict judicial decisions. We should remember, however, that recourse to experimental method in application to other kinds of data almost always results in more unsuccessful than successful predictions, and that this is true in the relatively mature and relatively simple natural sciences; that the development of a systematic, cumulative, communicable store of social knowledge about how and why judges make decisions is strictly a function of the relative quantity and quality of scarce resources that are allocated to its acquisition, and the proportion of such resources allocated to the study of judicial behavior has been and remains very small; and that our present ability to predict the outcomes of other social decision-making processes (i.e., those by legislators, presidents, electorates, business executives, and so on) certainly is no greater than in the case of judges. The relevant questions to ask at this time about the prediction of judicial decisions, therefore, are:

What kind of predictions, about what aspects of decision-making, and within what margins of error, are reasonable to expect of a science which remains in a very primitive stage of development?

To what extent is the non-scientist in a position to make more valid and more reliable predictions than the behavioralist, and to do this with a more parsimonious expenditure of time and other resources?

Obviously, if expectations are unreasonable, behavioralists are foredoomed to fail to satisfy the criteria that are posited for the evaluation of their accomplishments. One seemingly reasonable criterion, which frequently has been suggested in recent years, is whether the judicial behavioralist, with all of his [unnecessarily] complicated [and generally irrelevant] paraphernalia, can do any better than the average, experienced practitioner who is wise in the ways of courts and judges. So stated, the contest is readily recognizable as a recurrent theme in the sociology of knowledge: it is David versus Goliath; the pink-cheeked country lad against the city

- Holmes, supra note I, at $46 \mathrm{r}$. 
slicker; it is reason and common sense in opposition to sophism and scholasticism in their contemporary disguise..$^{10}$

\section{B. Professor Rodell versus Baker v. Carr:}

\section{$A$ tour de force majeure?}

As a concrete example of prediction by the expert in law who has no need for scientific impedimenta, we might take Fred Rodell's recent and already wellknown forecast of the outcome in Baker $v$. Carr. ${ }^{11}$ Some eleven days before the event, Professor Rodell correctly predicted that the United States Supreme Court would order the requested redistricting by a vote of five to four. He also stated that the majority would include Justices Black and Douglas, who would adhere to their dissents in Colegrove v. Green; ${ }^{12}$ Chief Justice Warren and Justice Brennan, who would "agree less militantly with Black" and "in that order of enthusiasm"; and Justice Stewart, who would "cast the deciding vote, in the sense that his vote [would] be the least firmly convinced and committed" but "for reasons not basically legal but rather personal and both extra-Court and intra-Court political."13 Professor Rodell thought that the dissenters would include Justice Frankfurter, who would adhere to his own opinion announcing the judgment of the Court in Colegrove; Justice Harlan, who would "join his mentor, Frankfurter, as a matter of course"; and Justices Clark and Whittaker, who would "silently side with Frankfurter."1k Colegrove would be "distinguished or, more probably, overruled"; and the opinion of the Court in Baker v. Carr would probably be written by Stewart, the most marginal justice in the majority, or possibly by Brennan, the next most marginal justice.

In fact, the decision in Baker v. Carr was 6-2 rather than 5-4. Mr. Justice Whittaker, who was on the verge of retiring three days later, did not participate; and Mr. Justice Clark concurred in the majority, with an independent expression of his personal view of the case. Colegrove was distinguished-indeed, practically embraced-in the opinion that Justice Brennan wrote for the Court; and Justice Stewart's concurrence made it quite clear that he was, indeed, the marginal member of the majority, which also included Black, Douglas, and Warren; and Frankfurter and Harlan wrote reinforcing dissenting opinions. Thus, Professor Rodell was correct in both his general and his specific predictions concerning the case, with the minor exceptions of Clark's vote in support of the majority and

${ }^{10} \mathrm{Cf}$. Strauss, An Epilogue, in Herbert J. Storing (ED.), Essays on the Sctentific Study of Pormics 307 (1962), for an extended articulation of this theme: a common-sensical defense of virtue against the depredations of the bette noire behavioral science. For less passionate and better-informed though equally antagonistic critiques of political behavioralism, see the papers by Russell Kirk and by Mulford Q. Sibley in Charcesworth, op. cit. supra note 8, at 49, 68.

${ }^{11} 369$ U.S. 186 (1962). Rodell, For Every Justice, Judicial Deference Is a Sometime Thing, 50 Geo. L.J. 700 (1962); the general and specific predictions are stated, id. at $707-08$.

${ }^{12} 328$ U.S. 549 (1946).

13 Rodell, supra note II, at 708.

14 Ibid. 
of Whittaker's non-participation; and even in this regard, he had ventured the contingent hedge that he would "not be too astounded to see either Clark or Whittaker join the majority rather than bolster a lost cause," although this too was qualified by the assertion that he would stick to his prediction of a "five-four vote for redistricting." ${ }^{\text {All }}$ An all, it seems fair to conclude prima facie that this constitutes an impressive, indeed, a spectacular, example of the skill of the legal expert to anticipate the probable outcome of a specific judicial decision.

One obvious question to ask about Professor Rodell's performance is: how did he manage to do it? In the introductory pages of his article, he informs his readers that it is and has been for many years his assumption that the votes of Supreme Court justices cannot adequately be explained in terms of such theoretical abstractions as judicial beliefs in activism or restraint, or in federalism as a constitutional principle. Much more basic are "a vast complex of personal factorstemperament, background, education, economic status, pre-Court career-of whose influence on his thinking even the most sophisticated of Justices can never be wholly aware."16 His own approach, therefore, has been to examine "the Justices individually as whole human beings"; and as examples of this approach in action, Professor Rodell next provided brief sketches of Black and Frankfurter, based upon his own subjective evaluation of everything that he then knew about both men. (These sketches make it clear that Rodell empathizes more with Black than with Frankfurter.) $)^{17}$ In reliance upon undisclosed but presumable similar evaluations of the remaining justices, Rodell then stated his predictions.

Up to this point, there would be little in the substance of Rodell's remarks to distinguish him from the judicial behavioralists with whom he appears to find himself in fundamental disagreement. They too have debunked legal principles as factors controlling decisions; ${ }^{18}$ it is they, rather than he, who have attempted to undertake systematic investigations of the effect of background characteristics upon decisions. ${ }^{19}$ They also affirm the experimental method and the testing of hypotheses by making explicit predictions. ${ }^{20}$ The judicial behavioralists agree that Black is much more liberal than Frankfurter; and some of them (just like

${ }^{28}$ Ibid.

${ }^{30}$ Id. at 700, 701.

${ }^{27}$ For a similar discussion but with the opposite empathy, see WaLlace Mendetson, Justices BracK AND FRANKFURTER: CoNFLICT ON THE COURT (I961).

${ }^{18}$ E.g., Schubert, Policy without Law: An Extension of the Certiorari Game, ${ }_{4}$ STAN. L. REv. 284 (1962).

10 E.g., Schmidhauser, The lustices of the Supreme Court: $A$ Collective Portrait, 3 Midwest J. Por. Scr. I (1959), and Schmidhauser, Stare Decisis, Dissent, and the Background of the Justices of the Supreme Cottrt of the United States, 14 U. ToronTo L.J. I94 (1962); or Nagel, Testing Relations between Judicial Characteristics and Judicial Decision-Making, I5 Westers Por. Q. 425 (1962); Nagel, Ethnic Affiliations and Judicial Propensities, 24 J. Porrmcs 92 (r962); and Nagel, Judicial Backgrounds and Criminal Cases, 53 J. CRrM. L., C. \& P. S. 333 (rg62).

${ }^{20}$ E.g., Tanenhaus, Supreme Court Attitudes toward Federal Administrative Agencies, 1947-1956-An Application of Social Science Methods to the Study of the Judicial Process, I4 VAND. L. REv. 473 (196r), or Tanenhaus, Schick, Muraskin \& Rosen, The Supreme Court's Certiorari Jurisdiction: Cut Theory, in Glendon Schubert (Ed.), Judicial Deciston-Makjng ( 1963 ). 
Rodell) have suggested that Frankfurter's ostentatious preference for deference is a mask for his own conservative predilections. ${ }^{21}$ Indeed, on the basis of my own $\mathrm{C}$ [civil liberties] Scale for the 1960 Term of the Court, ${ }^{22}$ which also was published in the same month as and prior to the decision in Baker v. Carr, anyone-not just a legal expert-ought to have been in a position to make precisely the same specific predictions about individual voting as did Professor Rodell-and anyone who had done so would have erred, just as Rodell erred, in regard to Clark. (For reasons that will be explained below, the outcome of Baker v. Carr-Rodell's general prediction-could not be forecast on the exclusive basis of the C Scale for the rg60 Term.) Therefore, not only would judicial behavioralists agree with the substance of most of Rodell's remarks; they would also have made precisely the same mistake in attempting to predict individual voting in Baker.

What, then, is there left to disagree about? Methodology and goals.

\section{What Kind of Prediction Is Most Important?}

Any judicial behavioralist known to me would consider it a waste of professional time to restate the theme of Charles Grove Haines' classic article, which was published in the Illinois Law Review over forty years ago.23 The article is wellknown, both among law students and undergraduate majors in political science; and no one (including Rodell) has succeeded in restating the general argument, that the personal values of judges are of fundamental importance in their decisionmaking, in a more articulate or a more thoughtful manner than did Haines. Yet, if one eschews any method more systematic than the necessarily unique, subjective evaluations that are a function of one's total competence, what more is there to be said when one tries to communicate to others the process by which one arrives at his judgments-and makes his predictions? Such a process also is the result of a "vast complex of personal factors-temperament, background, education, economic status, pre-[academic] career-of whose influence on his thinking even the most sophisticated of [Professors] can never be wholly aware:"

Rodell concluded his article with the opinion that, ${ }^{24}$

the infinite variety of quirks and causes that may determine human choice on any matter where man is at the mercy of his own mind are fortunately far beyond the predictive capacity of even the most intricately attuned and adjusted calculating machine ... [and] he who would analyze, predict, or understand the Supreme Court's constitutional decisions will fare considerably better if he concentrates on that same infinite variety of human factors which make precise prediction impossible....

${ }^{21}$ Spacth, Iudicial Power as a Variable Motivating Supreme Court Behavior, 6 Midwest J. Pot. Sar. 165 (1962); Schubert, The 1960 Term of the Supreme Court: A Psychological Analysis, 56 AM. Por. Scr. REv. 90, 101 (1962).

is Id. at 98 .

"Haines, General Observations on the Effects of Personal, Political, and Economic Influences in the Decisions of ludges, 17 ILx. L. REv. 96 (I922).

"Rodell, supra note $\mathrm{II}$, at 708 . 
It is not difficult, however, to demonstrate the contrary of this proposition:

(I) Recent research in the social psychology of judicial attitudes indicates that, far from being an infinite set, the number of basic attitudinal dimensions that are relevant to the decision-making of the United States Supreme Court is very small.

(2) Neither calculating machines nor the electronic digital computers (which are, apparently, the intended referrent) have any predictive capacity at all; all that computers can do is to perform very simple arithmetic operations. Predictions are made by human beings who design research and write programs which direct computers in their mundane tasks. The fundamental question is this: when the task is to make systematic measurement of the interrelationships among a large number of variables in relation to an extensive set of empirical observations, which instrument is likely to carry out the task with maximal reliability and a minimal number of mistakes? The subconscious mind of some individual scholar? Or the computer?

(3) Neither Rodell nor a computer is capable of concentrating upon an "infinite variety" of factors, human or otherwise. It is difficult enough to concentrate upon even a relatively small finite number of variables; and one difference between humans and computers is that the former do not concentrate upon, for example, all of the cells of even a small (say, ro x 10) matrix, either uniformly, consistently, or simultaneously, while the computer can be made to do this. The great virtue, and-from this special point of view-the great weakness of the human mind is that it abstracts from the variable matrix certain relationships for examination; only by thus focusing attention is concentration possible.

(4) For most purposes that I can think of, humans are much to be preferred to. computers; but for a few purposes, including some which relate to the processing of data about judicial decision-making, it seems foolish to waste such a scarce human resource as scholarly time and energies by expending them upon tasks that machines can perform better. To argue, therefore, that the legal expert can predict judicial decisions better than a computer is spurious, because such argument distracts attention from the real issue. In any rational allocation of resources, legal experts and computers would be doing different things-for the very good reason, as I have tried to explain, that legal experts are much smarter and, in terms of humanist (though not in terms of economic) criteria, much more valuable than computers.

For Rodell to have predicted correctly many aspects of the decision in the most important case to reach the Supreme Court in almost a decade is of mild interest, from a scientific point of view, but what is the social significance of the event? No doubt, other professors have anticipated the Supreme Court and other courts on previous occasions; and no doubt, successful practicing attorneys develop some 
skill in making similar predictions, at least in their own cases. ${ }^{25}$ What, however, if we were to have assembled a hundred professors of constitutional law, and induced them to make individual predictions about the Baker case, utilizing the same method (or, rather, lack thereof) as Rodell: how many would have agreed with him? How many of them would agree now, upon the significance of the decision and its probable effect upon the Court's decision-making in related cases during the current term?

Or, in the alternative, let us suppose that we give our legal expert (I don't care which one) a hundred cases, selected at random from among those set down for oral argument during the term. Although, for technical reasons that no doubt are familiar to readers of this journal, it would be a difficult experiment to perform empirically, let us assume that the legal expert has access to the records before the Court; and let us also assume that he has been present to hear oral argument for each case in his sample. He makes his prediction for each case immediately after oral argument, both as to outcome and in terms of the more specific details (such as Rodell included in his prediction). What will be his percentage of error?

I think it will be conceded that if perfect prediction were demonstrated to obtain, either in the absolute reliability of the judgments of the one hundred constitutional law professors, or in the absolute validity of the one hundred predictions of our legal expert, we should then have to resort to a theory of chance variation in order to explain the results; we should not expect perfection in either instance, nor should we be likely to encounter it empirically. It seems not unreasonable to make equivalent demands of predictions by judicial behavioralists: that they be correct within some previously stipulated margin of error adequate to assure that the results obtained would be extremely unlikely to have occurred merely as the result of chance variation. But even if the margin of error of the hundred legal experts with the single case, or the single legal expert with the hundred cases, were rather small-say, less than .05-neither performance would have social significance unless the requisite skills could be communicated to other persons. Perhaps they could; but if they could, we should then still have to talk about the methods of pedagogy which resulted in the inculcation of such a high attainment of professional skill.

For the judicial behavioralist, the question of methodology is not sublimated to the intuitional level; on the contrary, it is a critical consideration in any research design. (This is true, of course, of all scientific research.) Moreover, prediction is not an end in itself; it is, rather, a necessary aspect of the verification of theory; and the goal of scientific inquiry in judicial behavior is theoretical knowledge, not merely the ability to forecast which way some particular case will be decided. Usually, the outcome of any individual case is as irrelevant to the concerns of the

${ }^{25}$ Karl N. Llewelipn, The Common Law Tradition-Deciding Appeals 4, 6 (r960): "The fact is that the work of our appellate courts all over the country is reckonable... on an absolute scale, quite sufficiently for skilled craftsmen to make usable and valuable judgments about likelihoods.... [There is] a way of reckoning the forthcoming results which is not only that now used by the ablest and most successful appellate and drafting counsel, but is also available to any lawyer of ordinary intelligence." 
investigator as it is to the Court itself. Significance lies not in the individual decision, ${ }^{26}$ either of a single justice or of the Court, but rather is found in the uniformities that can be perceived best in the aggregate data for the decisions of several justices in many cases over a substantial period of time.

What is important to be able to predict, therefore, is what the Supreme Court (or any other judge or group of judges) is likely to decide in regard to a given issue, or set of issues, through time. The importance of the Supreme Court's policy-making function does not usually flow from the consequences to the immediate parties in a particular case; one evaluates such importance by making (explicitly or implicitly; loosely or precisely) probability statements about the likelihood of other parties inducing equivalent response from the Court if the same issue (or, to speak more exactly, another facet of the same issue) were to be raised again. It is by establishing trends of this sort that the Court makes policy; and these are the uniformities about which judicial behavioralists make predictions, because these are the more meaningful and important kind of predictions to make. The remainder of this paper discusses the attitudinal continuities manifest in both the individual and the group voting behavior of the justices of the Supreme Court during the most recently completed term; that discussion will then provide the basis for the set of predictions about the current (October, I962) term, with which the paper concludes.

III

\section{A Psychological Analysis of the ig6r Term}

\section{A. A Psychometric Model of the Supreme Court}

Since both a general statement of the theory and a technical description of the method have been published in some detail elsewhere, ${ }^{27}$ the present discussion will be limited to a simplified exposition of those aspects of the model that must be understood if the reader is to follow the ensuing analysis of empirical data. Let us assume that each justice entertains relatively well-structured attitudes toward the recurrent major issues of public policy that confront the Court for decision. If it were possible to identify the common issues, and the relevant attitudinal dimensions that are functions of these issues, then it might be possible to speak in some systematic way about the set of attitudinal dimensions that is most important for a particular group of justices-even though there were considerable variation in the

20 Id. at 6: "Reckonabilities [in the individual case], not 'statistical' or 'historical' reckonabilities, are in question. For it is a significant degree of reckonability in the individual case which the bar demands, and which the lay public expects, as a condition of its confidence. This is an inhuman demand to make on human machinery. The very reason that appellate courts exist is that there is doubt, that skilled men do not agree about the outcome. To require reckonability is therefore to require the absurdly impossible."

${ }^{27}$ Schubert, A Psychometric Model of the Supreme Court, American Behavioral Scientist, Nov. 1961, p. I4; Schubert, Psychometric Research in Judicial Behavior, 62M Modens Uses op Locic IN LAw [M.U.L.L.] 9-18 (1962); Schubert, The rg6o Term of the Supreme Court: A Psychological Analysis, 56 AM. PoL. Scr. Rev. 90 (1962); Schubert, $A$ Solution to the Indeterminate Factorial Resolution of Thurstone and Degan's Study of the Supreme Court, 7 Bekavoral Sciznce 448 (1962). 
direction and intensity of the attitudes of individual justices, as these might be measured on the relevant dimensions. Let us further assume, however far-fetched the notion might seem at first blush, that we can account for most of the important differences among the attitudes of a group of justices by using only three dimensions.

We might then conceive of a syndrome of attitudes for each justice, which we could symbolize and represent graphically as a unique point in the space defined by the three dimensions. Moreover, since the real space that most humans sense and think in terms of is three-dimensional, it will be convenient to employ the attitudinal dimensions as reference axes for an Euclidean space, and to use sets of Cartesian coordinates to locate in the space the point which represents the unique syndrome of attitudes of each justice. For convenience, we shall refer to such points as judicial "ideal-points," or, more simply, as $i$-points.

The cases on the Court's dockets might be conceptualized as complex stimuli, which (in effect) ask questions about issues to which the justices are asked to respond. It will be recalled that the number of issues that survive in any case, after appellate review below and the Supreme Court's jurisdictional screening are completed, are few and refined, in sharp contradistinction to the mutiplicity of issues that may have been raised during the trial and other earlier stages in the litigation of the case. Characteristically, the effect of what are called "the facts" of the case is to provide direction and intensity in defining the nature of the issue; that is, the issue specifies which attitudinal dimension is relevant, while the facts determine where a particular case is located on the dimension. We already have assumed that the issues raised by cases are the counterparts of the values of the justices, and that judicial attitudes mediate external values (represented by issues in cases) and internal values (which constitute the justices' own beliefs). Therefore, it is not unreasonable to assume that each case can be measured in terms of the same attitudinal dimensions as the justices, and represented by a [j] point in the same three-dimensional space.

If we could locate the $i$-points for the nine justices, together with the $j$-points for the one hundred and seventy-five cases decided on the merits in a typical term, in the same joint psychological space, then we should have, at least in principle, a deterministic model for predicting the votes of the justices, and therefore the decisions of the Court. To be more precise, each of our three reference axes would have a defined direction, and therefore the coordinates for any point ( $i$ or $j$ ) in the space would be within the range $+\mathrm{r.00}$ to $-\mathrm{r.00}$, in its orthogonal projection on each axis. In order to predict the decision in any case, it would be necessary only to measure the relationship between the $j$-point and the set of $i$-points. For convenience, let us speak of a positive difference between the coordinates, on a given axis, for two points being compared, as a measure of the dominance of the point which is more positive, over the lesser point. 
We might also assume that in comparing two points, $\mathrm{A}$ and $\mathrm{B}$, there might be a negative difference for $A$ on one dimension, and a positive difference on the other two dimensions, so that an excess (of whatever attitudes are being measured) on those dimensions would compensate for a deficiency on the first dimension, and we might then still speak of $A$ as dominating $B$, in the sense of the over-all balance of their relationships. More generally, any justice would vote to uphold an issue (such as freedom of speech) if, and only if, his sympathy for the issue was equal to or greater than the amount of sympathy required for anyone to agree with the claim raised in a case; or, in terms of our model, he would vote positively if and only if his $i$-point dominated the $j$-point.

Obviously, under these assumptions, the decision of the Court in any case would depend upon whether the $j$-point dominated, or was dominated by, a majority of $i$-points. In the simplest, one-dimensional case, all ten points would be arrayed along the same continuum; and the justices would be partitioned into two subsets (pro and con the issue) by the locus of the j-point. One subset could, of course, be empty; and unanimous decisions upholding an issue would occur when the $j$-point is dominated by all $i$-points, while unanimous decisions in the negative would occur when all $i$-points are dominated by the $j$-point. In the threedimensional case, the justices would be partitioned into two subsets by the plane orthogonal to the vector of the $j$-point.

Justices who are attitudinally in close agreement with each other ought to be located close to each other in our three-dimensional space; and we should expect such justices to agree in their voting. Justices who hold opposing views on such fundamental issues as civil liberties, or the proper role of government in the economy, ought to be located far apart in the space, and we should expect them to disagree often in their voting. Cases that raise questions of differing degrees of valuation about the same issue would be arrayed as a set of $j$-points along a single continuum, which we shall hypothesize to be a scale axis which transects the space. Of course, if such a scale axis should coincide with one of the three reference axes, this would be equivalent to saying that such a set of cases raised only the single issue represented by the one reference axis, and that these cases were quite independent (in a statistical sense) from the other two reference axes. We should anticipate, however, that most cases decided by the Supreme Court will not be univariate, which is equivalent to saying that most scale axes, representing sets of cases, will not coincide with any of the reference axes.

Moreover, we ought to anticipate that both $j$-points and $i$-points will be scattered in non-linear patterns in the space; and when we speak of a scale axis, we refer to a continuum (positioned in the three-dimensional space) which represents the average of the relationships of the relevant $j$-points with regard to the particular issue that we define. Stated otherwise, neither the $i$-points nor the relevant $j$-points necessarily lie upon a scale axis that represent the issue in which we are interested; 
but all project upon the scale axis, which is the line that is "closest" to all of the $j$-points in the defined subset.

We can define issues narrowly or broadly, depending upon what seems to be reasonable from an empirical point of view, based upon an examination of the value-content of the cases in any subset that is of interest. Thus, we might be interested in any or all of the following: (I) F.E.L.A. evidentiary cases; (2) all F.E.L.A. cases; (3) F.E.L.A. cases, Jones Act cases, Longshoremen and Harborworkers Act cases, maritime cases raising the question of seaworthiness, and so on; (4) both federal and state cases involving workers' claims for monetary compensation for industrial accidents; (5) any cases involving workers' claims for monetary compensation; (6) any cases involving the rights of workingmen; (7) any cases which raise the fundamental issue of economic liberalism and conservatism. In our model, any of these categories might constitute an issue which we could represent as a scale axis; but the last category clearly is by far the most basic of these seven categories, and we should understand it to include many kinds of public policy issues beyond those involving the rights of labor. If we were to plot a set of seven scale axes, corresponding to these seven categories, we should expect them to be highly intercorrelated with each other, which in geometric terms means that they ought all to traverse the space in the same general direction-indeed, the $E$ scale, representing the seventh category, would define the most general direction, from which the sub-scale axes, representing sub-variables of economic liberalism, could be expected to deviate both from each other and from $\mathrm{E}$.

Methods for locating $j$-points in the joint decision-making space have not yet been perfected. The relatively simple method which can be used to position i-points, and which we shall describe presently, depends upon the circumstance that there are a relatively large number of cases, and relatively few justices. In the average recent term of the Supreme Court, there have been a hundred split decisions and nine justices. This yields approximately a hundred different observations on the voting of each justice, in relationship to each other justice. If necessary, we could increase the number of observations by extending the time period under analysis. As we shall see, a hundred observations are enough to support stable correlations and analyses thereof; but we are never in a position to observe more than nine votes in a single case. This is too few for statistical manipulation to be meaningful. So voting data can be used to locate the spatial positions of $i$-points, but not of $j$-points. It seems most likely that it may be possible to develop methods for analyzing opinion data which will establish the position of a configuration of $j$-points in a joint space. Preliminary work along these lines, by two different investigators, is on the verge of publication at the time this is written; ${ }^{28}$ such an achievement would be a methodological break-through which would facilitate the use of the

${ }^{28}$ Kort, Content Analysis of Judicial Opinions and Rules of Law, in Grendon Schubert (ED.), Judiciar Decision-Making (1963): and Schubert, Attitudinal Dimensions of Tudicial Opinions and Votes: the Case of Robert Jackson (in press). 
model for the purpose of predicting decisions with much greater precision than now is feasible.

In the absence of a methodology for positioning individual cases in the space, we propose to resort to the alternative procedure of positioning sets of cases, as scale axes, in the space defined by the analysis of voting data. We shall first explain how we position the $i$-points. Then we shall explain how, by a quite independent method and set of observations, cumulative scales of judicial voting, on selected major issues, are constructed. We shall then position the cumulative scale axes in the space containing the configuration of $i$-points, thus (in effect) establishing the approximate location in the space of the cases in the scale sets. We assume that it will not be possible for anyone to fit the scale axes in positions consistent with those of the $i$-points, except with a specifiably low probability of chance success, unless the sets of observations and measurements, represented by cumulative scaling and factor analysis, are indeed equivalent. (They are, of course, theoretically equivalent to each other.) ${ }^{29}$ But if they can be demonstrated to be empirically equivalent, with the data for the 196r Term that we shall examine, we shall then be forced to choose between two hypotheses: either the relationship is due to chance variation, or the votes of Supreme Court justices are determined by their attitudes towards the issues in the cases that they decide.

\section{B. The Data}

The sample of decisions to be analyzed consists of all cases in which the Supreme Court divided on the merits during the period of the 196I Term, which extended from October 2, 1961, through June 25, I962. Both formal and per curiam decisions accordingly are included, but unanimous and jurisdictional decisions were excluded. As Table I indicates, almost two-thirds of the Court's formal decisions were reached over the disagreement of one or more justices, while this was true of only one-third of the per curiam decisions. In the preceding year, the proportions were approximately three-fourths and one-fourth, respectively. Moreover, it has not been unusual for the justices, in recent years, to disagree in a majority of their decisions on the merits (combining formal and per curiam), as they did during the rg6r Term; this was also true during twelve of the preceding fifteen terms. The average number of split decisions over the past sixteen terms was ninety-six, and

TABLE I

Summary of Decisions on the Merits, ig6i Term

\begin{tabular}{r|c|c|c}
\hline Decision & Formal & Per curiam & Totale \\
\hline Split........... & 63 & 20 & 83 \\
Unanimous..... & 39 & 41 & 80 \\
\hline Totals....... & 102 & 61 & 163 \\
\hline
\end{tabular}

${ }^{20}$ Clyde H. CoOmbs, A Theory of Data chs. I, II, I2 (in press). 
the average number of unanimous decisions on the merits was seventy-nine; in this respect, the $196 \mathrm{r}$ Term provoked somewhat less disagreement among the justices than has been usual.

Each case to which the Court had assigned a unique docket number and for which the Court had made a disposition on the merits, was a unit for voting analysis; and for each case, one set of from six to nine votes was counted. With eighty-three decisions on the merits, there would be potentially a total of 747 votes in the sample for analysis, assuming full participation in each case. In fact, there were a hundred less votes, primarily because of the illnesses which afflicted Justices Whittaker and Frankfurter during the late winter and early spring, resulting, in each instance, in the incapacitation and eventual resignation of the justice. Whittaker's last voting participation was on March 5, ig62, and his resignation became effective on April I of that year. Frankfurter's last voting participation was on April 9, but his resignation did not become effective until August 28, I962. Mr. Justice White, who replaced Whittaker, became a member of the Court on April I6, but he was able to participate, of course, only in cases subsequently argued, or decided summarily; his first participation was in Scholle v. Hare, ${ }^{30}$ which was decided per curiam and without oral argument, and he took part in the decision of less than a third of the remaining split decisions of the term on the merits.

One of the eighty-three cases could not be used in the analysis, because the Court divided 4-4, without opinion and with Frankfurter not participating, and there was no objective means of identifying the voting positions of the eight participating justices. Justices Douglas and Clark participated in all of the remaining eighty-two decisions; and Warren, Black, Harlan, Brennan, and Stewart, in all except one each. The remaining three -members of the Court during this term voted, however, in less than half of these cases: Frankfurter in thirty-eight, Whittaker in twenty-eight, and White in twelve.

Stated otherwise, Warren and Harlan each filed a jurisdictional dissent in a case which the rest of the Court decided on the merits, and in which at least one other justice dissented on the merits; these two jurisdictional dissents were treated as non-participations. Brennan, Stewart, and Black failed to participate in one case each; Whittaker was absent in five decisions immediately preceding his retirement; Frankfurter missed all forty-five decisions that were announced after he became ill; and White did not participate in thirty-two of the decisions in which the Court divided subsequent to his appointment. To the preceding total of eighty-seven non-participations, we must add the eight votes that could not be specified, in the case in which the Court divided equally, and also the five cases decided by an eightjustice Court, during the interim between Whittaker's resignation and White's appointment. Subtracting these one hundred non-votes from the potential maximum of 747 votes, we are left with 647 votes of ten justices on the merits of the substantive

${ }^{80}{ }_{369}$ U.S. 429 (1962). 
issues in eighty-two cases in which there was dissent; and these 647 votes constitute the universe of raw data which constitutes the basis for our factor analysis and the cumulative scaling.

\section{The correlation matrix}

\section{The Factor Analysis}

The initial condition precedent to any factor analysis is the construction of a correlation matrix. In the present study, the correlation matrix was based upon a set of fourfold tables which, in turn, were constructed directly from observations of the raw data: the 647 votes on the merits described in the preceding section of this paper. These votes were tabulated in terms of agreement and disagreement with the majority, in the decision of each case, for every pair of justices.

For any such pair, there are five possibilities in each decision: (I) both may agree in the majority; (2) both may agree in dissent; (3) the first member of the pair may vote with the majority, while the second dissents; (4) the second member of the pair may vote with the majority, while the first dissents; or (5) either or both members may fail to participate in the decision, in which event there is no score for the pair for that decision. In the tabulation of votes for the factor analysis, no attention is paid to the substantive variables to which the decisions relate; the sole criterion for the attribution of votes is agreement or disagreement with the majority of justices who controlled the disposition of the case.

It is most convenient to arrange the summary tabulation of agreement-disagreement, for each judicial dyad, in the form of a fourfold table such as Table II. The

TABLE II

Fourfold Table of Agreement-Disagreement, Douglas-Warren, 196x Term

\begin{tabular}{|c|c|c|c|c|}
\hline & & \multicolumn{2}{|c|}{ Warren } & \multirow{2}{*}{ Totals } \\
\hline & & + & - & \\
\hline \multirow{2}{*}{ Douglas } & + & 54 & 0 & 54 \\
\hline & - & 12 & 15 & 27 \\
\hline \multicolumn{2}{|c|}{ Totals....... } & 66 & 15 & 81 \\
\hline
\end{tabular}

table shows that Warren and Douglas dissented together fifteen times; this dis/dis $(-/-)$ cell is the one that contains the kind of information utilized in some earlier studies" of "dissenting blocs" of the Court. Similarly, Warren and Douglas agreed in sixty-nine of these eighty-one sets of votes; this is the sum of the major or positive diagonal (i.e., the $+/+$ and the $-/-$ cells), and this is the kind of information that was the basis for the "interagreement" bloc analysis of the earlier studies just cited.

${ }^{32}$ C. Herman Pritchett, The Roosevelt Court: A Study in Judicial Politics and Values, 19371947 (1948); Glendon Schubert, Quantitative ANalysis of Jodictal. Behavior. (r959). 
It is apparent from an examination of Table II that the weakness of the earlier approach was that, by concentrating upon the agreement between pairs of justices, the analysts ignored what is at least an equally important aspect of judicial voting behavior, and that is the ways in which justices disagree. Table II, for instance, shows that not only did Douglas and Warren disagree in a dozen of these decisions; they disagreed in a particular way. In all of these instances of disagreement, it was Douglas who dissented while Warren adhered to the majority. This finding certainly suggests that Douglas was more extreme in his dissenting behavior than Warren (or, as we shall observe presently in Table III, than any other member of the Court except Harlan, during this term). Moreover, the correlation coefficients, which are computed from the fourfold tables, are very sensitive to how votes are partitioned between the two cells of a diagonal, as well as to differences between the diagonals.

In order to measure precisely the relationship among the four cells of a fourfold table, phi correlation coefficients are computed. ${ }^{32}$ In the correlation matrix shown in Table III, phi ranges from +.7ro (for Harlan and Frankfurter) to -.615 (for Douglas and Frankfurter). Frankfurter, therefore, was the most extreme justice in the range of his agreement and disagreement; and he voted most frequently the same as Harlan, and least often in agreement with Douglas.

Since there were ten justices on the Court during this term, there are fourfold tables and correlation coefficients for each of forty-five dyads. ${ }^{33}$ All data were placed on punch cards, and the computation of phi coefficients was programmed for computer analysis. Since both matrices are symmetrical, and in order to conserve

o2 The phi coefficient is an approximation of the Pearsonian $r$ correlation coefficient; and it is appropriate to use the phi coefficient when, as is true of these data, the two distributions to be correlated reflect $a$ genuine dichotomy. It certainly seems warranted to consider the voting choice between agreeing with the majority, or dissenting, as a kind of true dichotomy. The phi coefficient is relatively simple to compute: it is the ratio of the difference of the cross-products of the diagonals of a four-fold table, to the square root of the product of the marginals. For the data of Table II:

$$
r_{\phi}=\frac{(54 \cdot 15)-(12 \cdot 0)}{(66 \cdot 15 \cdot 54 \cdot 27)^{1 / 2}}=\frac{810-0}{(1443420)^{1 / 2}}=+\frac{810}{1201.424}=+.674
$$

Evidently, the sign of the coefficient depends upon which diagonal cross-product is the larger; or, in other words, upon whether or not 2 pair of justices agree more than they disagree, and also whether they agree both in assent and in dissent, or (in other words) whether their disagrcement is divided equally or disproportionately between the cells of the diagonals. The maximum range of the phi coefficient is from +1 to -1 ; but these limits rarely are attained empirically, since the maximum size of phi is a function of the distribution of the marginals, and can be \pm 1 only when all four marginal frequencies are equal. Sec Cureton, Note on $\frac{\phi}{\phi} \max 24$ Psychometruxa 89-91 (1959).

${ }^{23}$ When factor analysis is performed by hand use of a calculator instead of utilizing a computer program, it is necessary to arrange the correlation coefficients in the form of a square symmetrical matrix, with the major diagonal filled with the estimates of the highest communality for each justice. For the techniques of factor analysis, the interested reader is referred to any of the several standard works on this subject, e.g., Harry H. Harman, Modern Factor Analysis (1960); Benjamin Fruchter, INtroduction to Factor Analysis (1954); Ravmond B. Cattell, Factor Analysts: An Introddction and Manual for the Psychologist and Social Scientist (1952); Louis L. Thurstone, Multiple-Factor ANALYsis (1947). 
TABLE III

Fourfold Tables and Phi Correlation Matrux, 196i Thrm

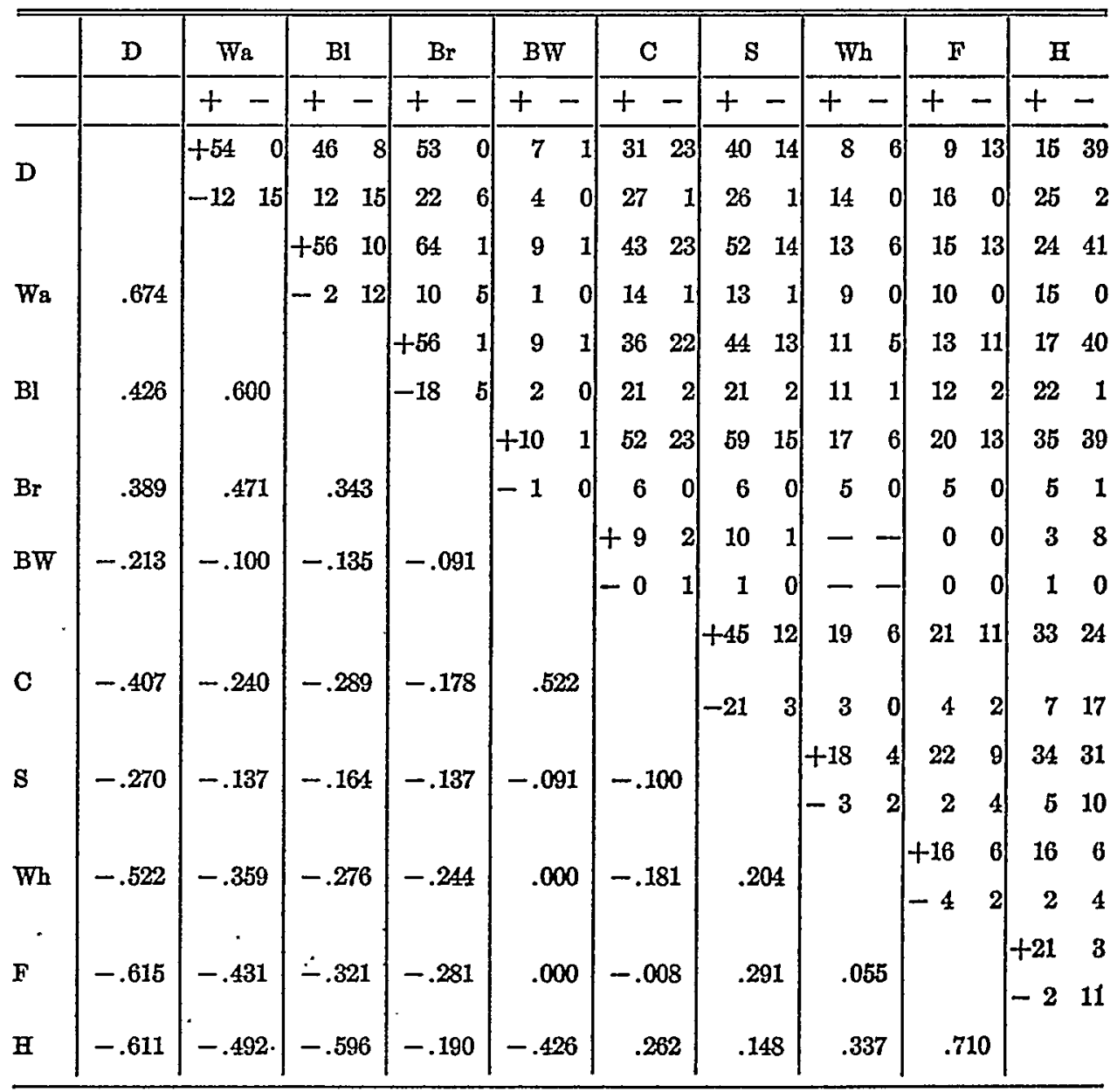

space, Table III presents the fourfold tables above the major diagonal, and the correlation coefficients below.

Before turning to the results of the factor.analysis of the correlation matrix, there are a couple of interesting findings that are apparent from a mere inspection of Table III. The most obvious is the sharp demarcation of eight of the justices into what appear to be two opposing blocs. Douglas, Black, Warren, and Brennan all correlate positively with each other, and negatively with the six remaining justices. Harlan, Frankfurter, Whittaker, and Stewart all correlate positively with each other, and negatively with the first group. White and Clark are not clearly associated with either bloc, although it should be observed that their relatively high positive correlation with each other hinges upon a single case, Robinson $v$. California, ${ }^{84}$ in ${ }^{34} 370$ U.S. 660 (1962). 
which they dissented together against a pro-civil liberty decision of the six other participating members of the Court.

Obviously, in the light of White's minimal participation during this term, relatively slight confidence should be reposed in the relationships that are denoted for him, either in Table III or elsewhere in this article. It should also be noted that White participated in no decisions with either Whittaker, whom he replaced, or Frankfurter, whose illness coincided with White's accession to the Court; in both instances, a zero correlation is reported in Table III, signifying the absolute statistical independence of White's voting behavior from that of Whittaker or Frankfurter. Clark, however, is positively correlated with Harlan, and his negative correlations with the other three members of the Harlan bloc are generally weaker than his negative correlations with the Douglas bloc. From this we might reasonably infer that Clark was not affiliated with either bloc, but that his disagreement was greater with the Douglas bloc. In view of White's maximal disagreement with Harlan, and his slight negative correlation with Stewart, it seems most likely, on the basis of the slim evidence available, that if he had participated in decision with Whittaker and Frankfurter, he would have been negatively correlated with them, too-and this is a proposition that we can re-examine, at a later point in this paper, in the light of evidence bearing upon the psychological distances separating these justices.

The general pattern that emerges from an examination of Table III, therefore, is that during the first six months of the term, the Court was divided into two opposing blocs of four justices each, with Clark unaffiliated but leaning towards the Harlan bloc. After Whittaker's retirement, the Court was divided into the Douglas bloc of four justices, and the still opposing Harlan bloc, now consisting only of himself and Stewart; and both White and Clark were unaffiliated with either bloc, although Clark was positively and White was negatively associated with Harlan.

Further evidence of the extent of polarization of the Court is provided by an examination of the dis/dis cells of the fourfold tables in Table III; for convenience, this information is summarized in Table IV.

TABLE IV

Total of Joint Dissents (Selected Justices, by Pairs)

\begin{tabular}{|c|c|c|c|}
\hline$\cdot$ & & $\mathrm{D}$ & H \\
\hline & $\begin{array}{l}\mathrm{Wa}, \mathrm{El} \ldots \ldots \ldots \\
\mathrm{C}, \mathrm{S}, \mathrm{F} \ldots \ldots \ldots \ldots\end{array}$ & $\begin{array}{r}30 \\
2\end{array}$ & $\begin{array}{r}1 \\
38\end{array}$ \\
\hline
\end{tabular}

It seems obvious that Douglas, Harlan, and the respective justices with whom each tended to associate in these dissents, were in pretty sharp and basic disagreement over something; and unless we are prepared to accept the somewhat implausible notion that they just could not get together over the meaning or application of the 
principle of stare decisis, ${ }^{35}$ then it may not be unreasonable to entertain the hypothesis that these groups may have been in disagreement about the social, economic, and political values that the Court upholds in its decisions.

\section{The factor loadings}

The initial product of a factor analysis is a set of derived correlations or ("loadings," as they customarily are called) which purport to measure the extent to which each element of whatever has been associated in the correlation matrix, is related to the components or dimensions into which the basic correlation matrix has been broken down. In the present study, the elements are the justices, and the factor loadings purport to express the correlation of each justice with the basic underlying dimensions of the phi matrix. Although it is technically possible to extract as many factors as there are elements which are intercorrelated in the phi matrix-ten, in the instant case-only five factors actually were computed, and of these, only three will be used for purposes of testing the principal hypothesis. The reason for limiting the number of factors to three is twofold: (I) the residual matrix, representing the amount of variance unaccounted for by the first three factors, was very small, and less, indeed, than the estimated error variance; and (2) three factors can be given an Euclidean graphical representation which accords with the spatial intuitions of most readers.

The usual procedure in factor analysis is to rotate the orthogonal factor axes, which are the direct product of a complete centroid routine, to oblique positions that are presumed to correspond to some criterion related to empirical reality, and thus to make possible a more meaningful psychological interpretation than would usually be possible if the orthogonal axes were retained. ${ }^{38}$ The orthogonal axes have not been rotated in the present study, but for the reason that, contrary to the usual procedure, reliance is not placed upon the association of substantive meaning with the factors. Substantive meaning is associated, instead, with the scale axes which are passed through the space defined by the orthogonal factor axes; and thus the scale axes-which are oblique-perform the same function, for purposes of interpretation, that is usually accomplished by rotation of the orthogonal axes. The orthogonal axes are used, therefore, only as a set of reference axes, which define the three-dimensional space in which the $i$-points of the justices and the $j$-points of the cases are located. And the factor loadings, shown in Table V, function as Cartesian coordinates which locate the $i$-points of the justices in the factor space.

Factor loadings can vary, in principle, from $+\mathrm{I}$ to $-\mathrm{I}$; in practice, their variance is, of course, bounded by the extremity of the correlation coefficients upon which

${ }^{a 5}$ Cf. Kort, Content Analysis of Judicial Opinions and Rules of Law, and Schubert, Civilian Control and Stare Decisis in the Warren Court, in Glendon Schubert (Ed.), Judicial Decision-MLnking (1963).

${ }^{36}$ Perhaps it should be noted, for the benefit of those readers who are not familiar with the method, that orthogonal axes are statistically independent, while oblique axes are correlated with each other; therefore, the implication of making a factor interpretation based directly upon a system of orthogonal axes is that one is prepared to make the assumption that there is no relationship among the factors, which must be conceived to be independent of each other. 
TABLE V

FActor Loadings for JUdicial IDeAL-PoInts, I96r TerM

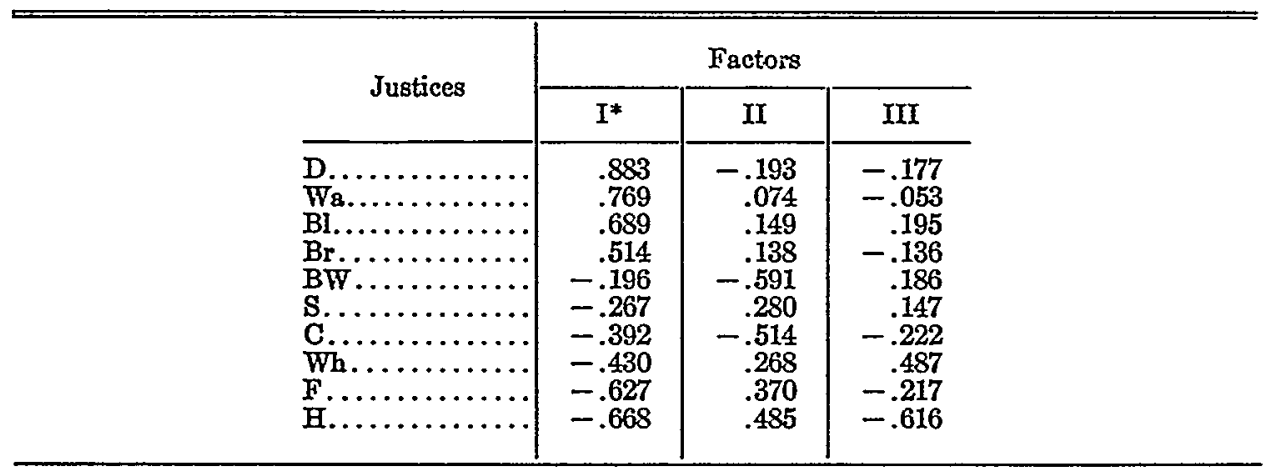

they are based. It will be observed that, on the average, the highest loadings (both positive and negative) are on the first factor, and that the mean magnitude of the third factor loadings is smallest. This is inherent in the centroid routine, which assumes that the first factor, to which the largest portion of the variance is attributed, is the most important factor, and so on. The loadings on the first factor range from a high of approximately +.88 , for Douglas, to a low of -.67 , for Harlan. Obviously, the justices are partitioned on the first factor into the same two blocs that were manifest in the phi matrix; but it is notable that the groupings on the second and third factors are quite different.

Thus, mere inspection of the factor matrix of Table $\mathrm{V}$ suggests that the multidimensional relationship among the justices is going to be somewhat different, and certainly more complex, than the simple bifurcation of a single dimension which will account for much, but not enough, of the variance in the voting behavior of the justices. For deeper insight than a single dimension-even when it is overwhelmingly the most important dimension-can afford, we must turn to an examination of the richer complexity made possible by work with the threedimensional factor space.

\section{The Cumulative Scales}

Cumulative scaling is a research operation that is completely independent from factor analysis. It may be undertaken before, at the same time, or after the factor analysis is completed. In cumulative (or Guttman) scaling, one examines the same universe of raw data that is used for the factor analysis. But instead of tabulating votes by dyads in terms of agreement with the majority, for scaling purposes votes are tabulated by cases, and are classified as being either in support of, or in opposition to, certain defined scale variables. The variables employed in this study were identified on the basis of experimental work in previous terms of the Warren Court. The basic procedures for cumulative scaling have been discussed elsewhere, 
although the format of Figures $\mathrm{I}$ and 2 below differs somewhat from that exemplified in the cited work. ${ }^{37}$

Consistent votes in support of the scale variable are denoted by the symbol $\mathrm{x}$, and inconsistent positive votes by $\underline{x}$. A blank space indicates a consistent negative vote, and the symbol - is used to signify an inconsistent negative vote. An asterisk signifies non-participation, and a slash bar indicates that a justice was not a member of the Court at the time a case was decided. Scale scores are simple functions of scale positions, and a justice's scale position is defined as being fixed by his last consistent positive vote. Where one or more non-participations separate a justice's consistent positive and negative votes, his scale position is assumed to be at the mean of the non-participation or non-participations, since it cannot be determined how he might have voted. A justice's scale score is computed by use of the formula:

$$
s=\frac{2 p}{n}-1
$$

where $s$ is his scale score, $p$ his scale position, and $n$ equals the number of cases in the scale. Scale scores, like correlation coefficients and factor loadings, can range in value from $+I$ to $-I$, with the significant difference that in practice, scale scores frequently attain these extreme values, reflecting the extremity of attitude of several of the justices in each of the scales shown in Figures $I$ and 2.

Two coefficients appear at the bottom of each scale; each of these purports to measure the degree of consistency in the set of votes that is being scaled. $R$ is Guttman's coefficient of reproducibility; .900 or better is conventionally accepted as evidence to support the hypothesis that a single dominant variable has motivated the voting behavior of the justices in the set of cases comprising the sample. $S$ is Menzel's coefficient of scalability $;^{38}$ it provides a more rigid standard than does $\mathrm{R}$, because $S$ (unlike $R$ ) does not capitalize upon the spurious contribution to consistency that arises from the inclusion in the scale of either cases or justices with extreme marginal distributions. Menzel has suggested that the appropriate level of acceptance for $S$ is "somewhere between .60 and .65 "; the scales presented in Figures $I$ and 2 are well above the suggested levels of acceptability for both $\mathrm{R}$ and $\mathrm{S}$.

\section{The C Scale}

Figure $I$ is a cumulative scale of the thirty-nine civil liberties cases that the Court decided non-unanimously on the merits during the 196r Term. In content, the $C$ variable is defined broadly to include all cases in which the primary issues

\footnotetext{
${ }^{37}$ Glendon Schubert, QuanttTative Analysts of Judicial Behnvior 270-90 (1959). In Figures I and 2 cases are cited to the official United States Reports: the digit preceding the slash bar is the third digit of the volume number, and should be understood to be preceded, if 8 or 9 , by the digits 36 ; and if 0 , by the digits 37 . The number following the slash bar is the page cite; and if more than one case begins on the same page, a docket number follows the page cite, from which it is separated by a colon.

${ }^{38}$ Menzel, A New Coefficient for Scalogram Analysis, 17 Pub. Orin. Q. 268-80 (1953).
} 


\section{FIGURE :}

Judictal Attutudes towards Civil Liberties, ig6r Term

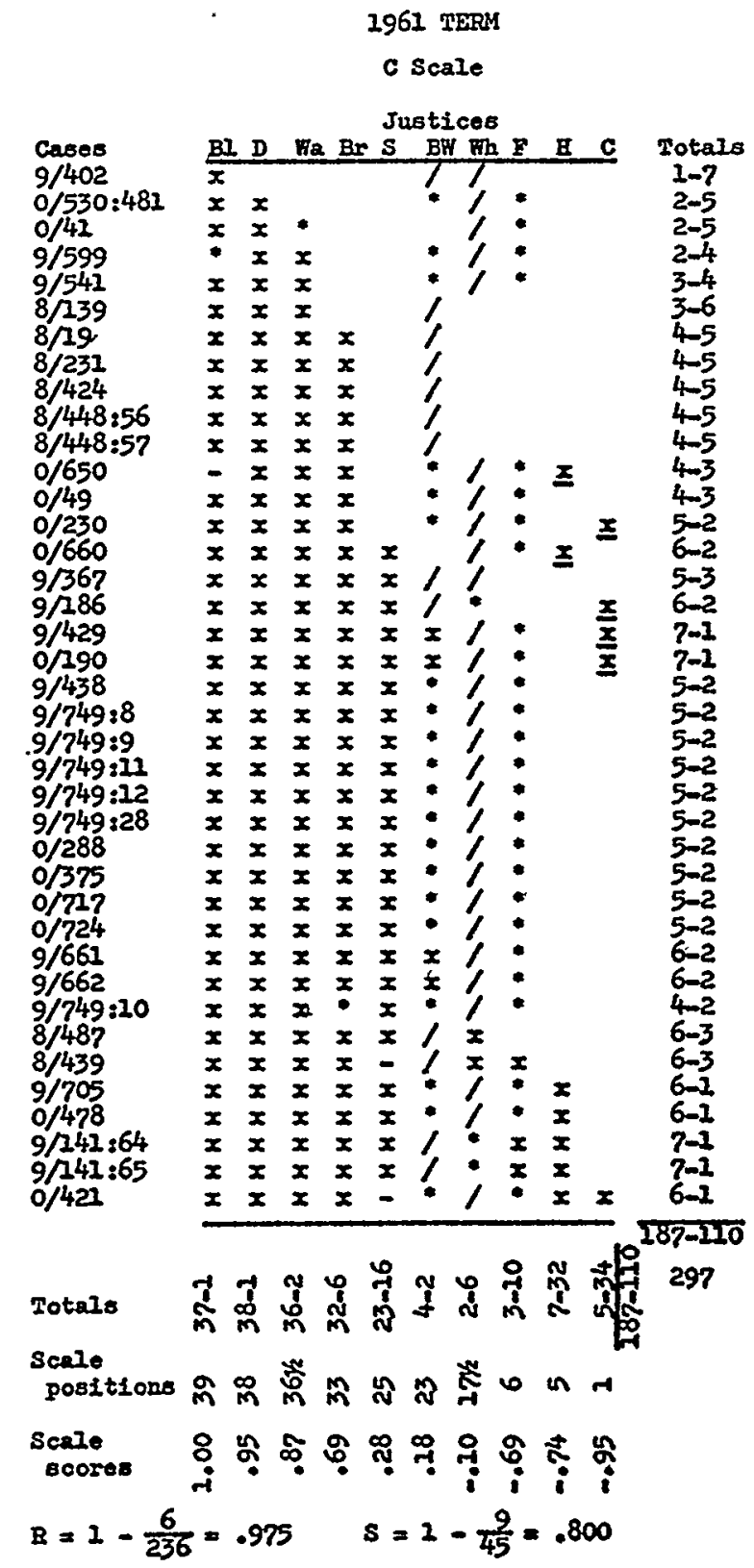


involved a conflict between personal rights and claims to liberty, and governmental authority:

(x) Political equality (e.g., white primary, integration, reapportionment),

(2) Political freedom (e.g., speech, association, press),

(3) Religious freedom (e.g., exercise, separation),

(4) Fair procedure (fifth, sixth, and eighth amendment rights), and

(5) The right to privacy (fourth amendment, psychological, physiological).

The number of cases included in the scale-almost half of the total-was about the same as in other recent terms; and the ranking of justices on the scale was very similar to the rankings for the 1959 and r 960 Terms, and precisely the same as in I958; the only differences from the r960 C Scale, for example, were the reversal of Black and Douglas in I96I, and the tie between Frankfurter and Harlan in $1960 . .^{80}$ Certainly, these are differences of minimal importance, since the Black-Douglas reversal hangs upon a single vote, and another single vote change would have resulted in a Frankfurter-Harlan tie. However, the extent of non-participation for White, Whittaker, and Frankfurter is so large that, although we are confident that their rank order is correct, much less confidence can be reposed in the precise scale scores denoted for these three justices.

The scale confirms what most scholars certainly believe to be the ideological patterning of the justices on civil liberties issues: Black and Douglas are most extreme in their support, followed by Warren, and then Brennan; Stewart is the marginal justice; and-skipping over the three justices with high non-participationHarlan and Clark give very slight support to civil liberties claims. Moreover, the differentials are in precise accord with those assumed by Professor Rodell for his prediction of Baker $v$. Carr, with the possible exception of Clark's ranking below Frankfurter and Harlan. In this regard, it is notable that three of Clark's four inconsistent votes-those in Baker v. Carr, ${ }^{40}$ Scholle v. Hare, ${ }^{41}$ and W.M.C.A. v. Simon ${ }^{42}$-came in state legislative reapportionment cases. Evidently, on this particular issue, Justice Clark's attitude was inconsistent with his more gencral attitude toward civil liberties questions, or at least, so it seems when all civil liberties issues of the term are squeezed into the less flexible mold of a single dimension. However, reference to Figure 3 and Table VII, infra, will show that Clark's votes in these three cases were not inconsistent when the civil liberty variable is viewed as an axis in three-dimensional space.

Mr. Justice Stewart was indeed the most critical decision-maker in these civil liberties cases. Because of his central position, and relatively moderate attitude, he was in the majority in thirty-four of these thirty-nine decisions-more than any

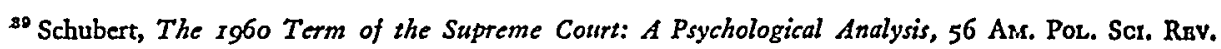
$90,98(1962)$.

${ }_{10} 369$ U.S. 186 (1962).

1169 U.S. 429 (1962).

¿s770 U.S. I90 (r962). 
other justice. A justice in the fifth rank can function literally as the determinative voter, however, only when there is full participation by nine justices, which occurred in only eight of these cases; or else when an even number of justices participate, and in such a way that the justice in the fifth rank might vote to create a tie, thus preventing the formation of a majority which could upset the decision below. In all five of the cases in which his colleagues divided 4-4, Stewart joined with the justices to his right to form majorities against the civil liberties claims; in the 5-3 and 4-2 decisions, he joined the more liberal colleagues to his left rather than to create an even division of the Court.

It is certainly noteworthy that over a wide range of specific issues, Black and Douglas and Warren together cast a total of only four negative votes; while Clark, with the exception of his three votes in the reapportionment cases, discovered only two among the remaining thirty-six civil liberties claims that were sufficiently meritorious for him to uphold. Turning from the extreme voters to the extreme cases, the one which raised the least persuasive civil liberty claim was Murphy $v$. United States, ${ }^{43}$ a per curiam decision which confirmed the unanimous ruling, announced two weeks earlier, that pre-indictment motions to suppress evidence on fourth amendment grounds are not appealable. Black wrote no opinion to explain why he alone, among the justices, differentiated between Murphy, and the decision in DiBella v. United States. ${ }^{44}$ At the bottom of the scale is Engel v. Vitale, ${ }^{45}$ the New York public school prayer decision announced on the final day of the term; here Stewart did articulate his views, which were to the effect that the Court, and not he, was being inconsistent in this decision. Evidently, the inference that one would have to make on the basis of this scale is to the contrary.

\section{The E Scale}

Figure 2 is a cumulative scale of the thirty-four cases dealing with economic policy issues that the Court decided non-unanimously on the merits during the rg6r Term. Economic liberalism (E+) means, in general, to favor the interests of the economically underprivileged, and to oppose affluence and monopoly power. More explicitly, it includes the following major components:

(I) To uphold the fiscal claims of injured workers in Federal Employers' Liability Act cases, in Jones Act and other maritime cases, and in state workmen's compensation diversity-jurisdiction cases; of tort claimants against the government; and of small, inferior claimants against the national government; but to favor the national government over large, corporate claimants (such as banks, railroads, power companies, and gold mining companies) and to uphold the government in eminent domain cases.

(2) To uphold governmental regulation of business "in the public interest."

48 369 U.S. 402 (x962).

“369 U.S. 121 (I962).

${ }^{48} 370$ U.S. 421 (1962). 


\section{Judicial Atritudes towards Economic Liberalism, ig6t Term}

FIGURE 2

Cases


$9 / 95$
$0 / 76$
$0 / 451$
$9 / 60$
$9 / 134$
$0 / 173$
$8 / 403$
$8 / 20$
$9 / 153$
$0 / 165$
$0 / 626$
$8 / 324$
$8 / 464$
$9 / 463$
$9 / 482$
$9 / 527$
$8 / 81: 17$
$8 / 81: 18$
$9 / 355$
$0 / 114$
$0 / 195$
$8 / 360$
$9 / 404: 77$
$9 / 404: 94$
$9 / 643$
$9 / 698$
$0 / 31$
$0 / 254$
$0 / 460$
$8 / 370: 23$
$8 / 370: 24$
$0 / 607$
$8 / 208$
$8 / 35$


lis
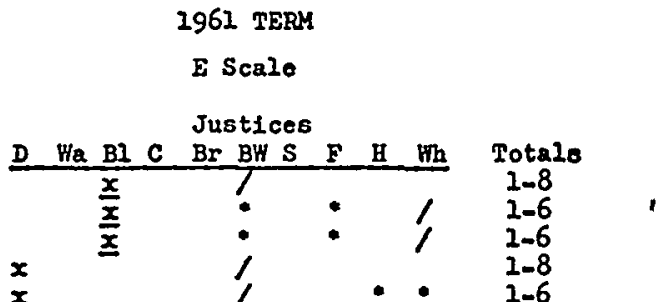

$x$

$x x$

$x \times x$

$x \times x$

$x \times x$

$x \boldsymbol{x} x$

$x x x \geq$

$x \times x>x$

$x \geq x \geq x$

$x \times x \times x$

$x \quad x \quad x \quad x$

$8 / 3.5$

Totels

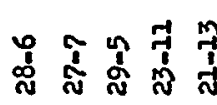

$y$
$y$
$y$
$y$

స

$5-3$

6-3

$1 \quad 6-2$

, $\quad 6-2$

$16-6-1$

Scale มู

273

(3) To uphold unions in labor-management disputes; to favor unions representing workers over unions acting in a management capacity; and to uphold unions rather than individual workers in disputes over dismissals, union security, and hiring halls.

(4) To oppose monopoly; to favor competition in patent infringement or patentability suits; to favor individuals over larger or corporate groups; and to favor small business over larger corporations. 
(5) To uphold state taxation on constitutional grounds (such as the commerce clause or the due process clause of the fourteenth amendment).

Although research in depth over several recent terms demonstrates that subscales of each of these components are very highly intercorrelated, both the highest consistency in judicial voting, and the highest proportion of pro (E+) decisions, occur in the F.E.L.A./Jones Act cases. Indeed, the research done thus far suggests that judicial attitudes toward workmen's compensation, and other fiscal claims of injured workers against employers, are an excellent index to even broader attitudes toward general liberalism, which we might define as a paravariable combining $\mathrm{C}$ and $\mathrm{E}^{40}$

The number of cases included in the E Scale-about forty per cent of the total split decisions on the merits for the 196x Term-is about average for recent terms. The ranking of the justices on this scale was similar to the rankings for the $1960,{ }^{47}$ 1959, and $195^{8}$ Terms, although there were three pair reversals in $196 \mathrm{I}$ which differ from the pattern of the previous terms: it is unusual for Warren to precede Black, or for Clark to precede Brennan, or for Frankfurter to precede Harlan on a term E scale. Moreover, the evidence in the scale to support these transpositions, in the present rankings, is so slight, that they would appear to be clearly within the range of error variance for the Ig6I Term E Scale. The differential for Warren and Black is a single vote, and an examination of the marginals of Figure 3 shows that Black voted E+ more and E- less frequently than any other member of the Court.

On the other hand, an examination of the case that made the difference, Blau $v$. Lehman, ${ }^{48}$ shows that Black's vote, upholding stock profiteering through interlocking directorates and trading on insider information, and rejecting the policy position of the Securities and Exchange Commission, was clearly an economically illiberal vote; and in addition, his choice was so consciously made that he wrote the opinion of the Court, having assigned the opinion (as the senior associate justice voting with the majority) to himself, the Chief Justice being in dissent. Such data tend to support the technical requirements of scale construction which account for Black's ranking below Warren this term.

Ranking Clark higher than Brennan also depends upon a single vote, although

${ }^{10}$ For an analysis of the interrelationships among scales and scale axes of the first and third of these subvariables, together with the civil liberties and economic liberalism variables, and the liberalism paravariable, during the middle years of the Roosevelt Court, see Schubert, $A$ Solution to the Indeterminate Factorial Resolution of Thurstone and Degan's Study of the Supreme Court, 7 Befavioral Screvce 454-57 (1962). For other scale analyses, of the second (anti-business) and the third (pro-labor) component subvariables, see Spaeth, Warren Coutrt Attitudes Toward Business: the " $B$ " Scale, in GlENDow Schumert (ED.), Judicial Decision-Making ch. 4 (1963), and Spacth, "An Analysis of Judicial Attitudes in the Labor Relations Decisions of the Warren Court," pp. 1-25 (mimeographed paper read at a panel of the Midwest Conference of Political Scientists, April 1962).

${ }^{67}$ The E Scale for the $1960 \mathrm{Term}$ is reported in Schubert, The 1960 Term of the Stupreme Court: $A$ Psychological Analysis, 56 AM. Poz. Scr. REv. 90, 100 (1962).

${ }^{48} 368$ U.S. 403 (1962). 
in this instance, the voting marginals support the order shown in the scale. Once again, moreover, an examination of the relevant case, Mechling Barge Lines $v$. United States, ${ }^{49}$ indicates that the choices made by the two justices were quite deliberate, and that the discrimination made between them by the $E$ scale for this term is a valid one. Brennan wrote for a majority which upheld an anti-competition decision of a three-judge district court, relating to profits already realized under long-haul/short-haul rate discriminations by a group of railroads, with the support of their acolyte, the Interstate Commerce Commission; Clark wrote the dissenting opinion, in behalf of Douglas and Warren and Black, protesting the Court's unwillingness to facilitate redress of the economic injury suffered by the competing barge lines which were plaintiffs in the case. Since the division was 5-4, Brennan's illiberal vote was decisive, and he made a clear choice to support the more conservative group of four justices on this issue.

The Frankfurter/Harlan reversal stems from two cases that were joined for common disposition, United States v. Drum and Regular Common Carrier Conference $v$. Drum $^{50}$ Frankfurter joined in an opinion of the Court which upheld the extension of governmental regulation over motor carriers; Harlan dissented in behalf of unregulated private enterprise. Notwithstanding Frankfurter's substantial nonparticipation, it should be noted that it is unlikely that full participation would have resulted in any change in his rank position; the same remark applies to Whittaker as well. With White, full participation might have resulted in a higher rank; and with the exception of White, there is a perfect correlation between the proportions of the marginals and the scale ranks of the justices.

Douglas, Black, Warren, and Brennan-the justices who are commonly recognized as the most liberal members of the Court during the past half dozen termsscale as economic liberals, as well as liberals on the C Scale. Similarly, Whittaker, Frankfurter, and Harlan have negative scale scores, and are among the lowest four ranks, on both scales; while Stewart and White both have moderate scale scores and occupy middle ranks, between the liberal (Douglas) and conservative (Flarlan) groups, ${ }^{51}$ on both scales.

The only justice whose rank on the two scales shows considerable change is Clark, who is tenth on $C$ but fourth on $E$, which suggests that Clark is a moderate liberal in his attitude toward issues of economic policy, and a pronounced conserva- tive in regard to civil liberties. This finding is quite consistent with those for other recent terms; in the 1960 Term, for instance, Clark ranked fifth on $\mathrm{E}$ and last on $\mathrm{C}$. On the other hand, six of the justices (Douglas-Warren-Brennan-Stewart-Frankfurter-Harlan) maintain precisely the same ordinal relationship, among themsclves, on both the $\mathrm{C}$ and $\mathrm{E}$ scales for the rg6r Term, which suggests that their responses

368 U.S. 324 (196r).

80 368 U.S. 370 (I962).

81 As in the 1960 Term, Douglas was the justice whose scores and rank on both scales identify him as the most generally liberal justice; while Harlan, in terms of the same criteria, is the most generally conservative justice. (The most conservative justice in the previous term was Frankfurter.) 
to issues of both civil liberty and economic policy were functions of more generalized liberal and conservative orientations.

The three cases at the top of the E Scale, in which Black alone voted (and in terms of this linear analysis, inconsistently) to uphold the liberal position, raise the question whether these three cases, and the three which follow in which Douglas dissented alone, relate to two different components (or subvariables) of the scale. Examination of these six cases demonstrates, however, that such an assumption is false. In each of the two sets of three cases, there is one case involving the second component (governmental regulation of business), one case involving the third (labor-management relations), and one involving the fifth (the constitutionality of state taxation of interstate commerce). All three Douglas dissents were on grounds which are highly doctrinaire, which supports the attribution to him, by the scale, of the most extremely liberal views of any of the justices on issues of economic policy.

Black's dissents have two obvious common characteristics: in each case, he protested against a decision which had the effect (as he argued) of retreating from previously established liberal salients in what were formerly highly controversial areas of public policy, and each of these issues was one in which Black personally had been intimately involved-either as a Senator or as a Justice-in the struggle for the establishment of a more liberal policy. Thus, in the first case on the scale, Black dissented on behalf of labor's hard-won right to strike. ${ }^{52}$ In the second, the invalidation of a regulation (of the Secretary of Agriculture) intended to prevent interstate competition in milk marketing evoked, for Black, the unpleasant recollection of United States $v$. Butler, ${ }^{53}$ which impelled him to discuss the legislative history' of New Deal statutory language that he had helped to create; and in the third, Black dissented on behalf of effective state regulation of the insurance business-but the interpretation of the McCarran-Ferguson Act, which was nominally at issue, must have been viewed, by Black, in the context of his own role in United States $v$. South-Eastern Underwriters Ass $n$, ${ }^{54}$ which was, in effect, overruled by the McCarran-Ferguson Act.

In short, our interpretation of Black's vote in these three cases is psychological rather than legal: the intensity of his earlier personal involvement in these particular issues was so great that he now, years later, committed perceptual "errors" which caused him to evaluate the importance of the contemporary decisions differently than did his colleagues. In more strict psychometric terms, Black's perception of the loci of the $j$-points of these three cases, in the three-dimensional space of our model, differed from the apparent consensual perception of the other justices. The other justices thought that these cases raised extreme claims, which would locate their

\footnotetext{
02 "It took more than 50 years for unions to have written into federal legislation the principle that they have a right to strike." Mr. Justice Black, dissenting in Teamsters Local v. Lucas Flour Co., 369 U.S. 95, $\log$ (Ig62).

63297 U.S. I (1935).

*4 322 U.S. 533 (I944).
} 
$j$-points near the positive terminus of the $\mathrm{E}$ scale axis in Figure 3; but Black perceived these to be moderate claims, represented by $j$-points located either near the origin or else. with negative reference coordinates on the first factorial axis.

\section{The Minor Scale Variables}

In addition to the two major variables that have been discussed, there are four other variables that have been tentatively identified, on the basis of similar research in other recent terms of the Court. These include $\mathrm{F}$ (either the national or state governments versus taxpayers, when the issue is statutory or administrative rather than constitutional); A (judicial activism or restraint in reviewing the decisions of the Congress, the President, and administrative agencies); $N$ (federalism, and conflict between the national and state governments); and $J$ (the supervisory authority of the Supreme Court over the decision-making of lower courts). There were fourteen split decisions on the merits in non-constitutional taxation cases during the 1960 Term, and these formed an acceptable $F$ scale..$^{55}$ There were also enough F cases to form scales in the 1959 and 1957 Terms. Working in depth with a sample of cases drawn from several terms, Spaeth has used cumulative scaling to analyze an attitudinal dimension that seems to be very similar to the variable which we have denominated $J^{66}$ There have been too few cases associated with A, N, or J, for any of these variables to be scaled on the basis of term data, in recent years.

In the Ig6r Term, there were three cases on $F$, three on $A$, two on $N$, and none on $J$; there was one decision that could not be classified in terms of any of these variables; and there was also the one 4-4 decision (the effect of which was E-) for which objective attribution of the votes was not possible. These ten cases, plus the thirty-nine C Scale and the thirty-four E Scale cases, account for the total of eightythree split decisions, on the merits, for the term; and it is evident that together, the two major liberalism variables account for the variance in the voting behavior of the justices in eighty-eight per cent of these decisions.

E. Scale Axes in the Factor Space

The next step is to position the scale axes, which are considered to be the psychological analogues of the cumulative scales, in the space defined by the factorial reference axes. It will be recalled that the configuration of $i$-points for the justices is uniquely determined by the set of factor loadings given in Table $V$. The problem now is to determine whether it is possible to pass a set of axes through the factor space, in such a manner that the rankings of the projections, from the $i$-points onto the axes, are equivalent, in a statistically acceptable sense, to the rankings of the justices on the scale axes. What is required mathematically, in order

ss The F Seale for the 1960 Term is reported in Schubert, The 1960 Term of the Supreme Court: $A$ Psychological Analysis, 56 Au. Pot. Scr. Rev. 90, ror (Ig62).

so Spaeth, Judicial Power as a Variable Motivating Supreme Court Behavior, 6 Midwesr J. Pou. Ser. $54-82(1962)$. 
FIGURE 3

Scale Axes and the Judicial Point Configuration in the Orthogonal Factor Space

FIGURE $3 \mathrm{~A}$

REFERENCE AXES I* AND II ${ }^{57}$

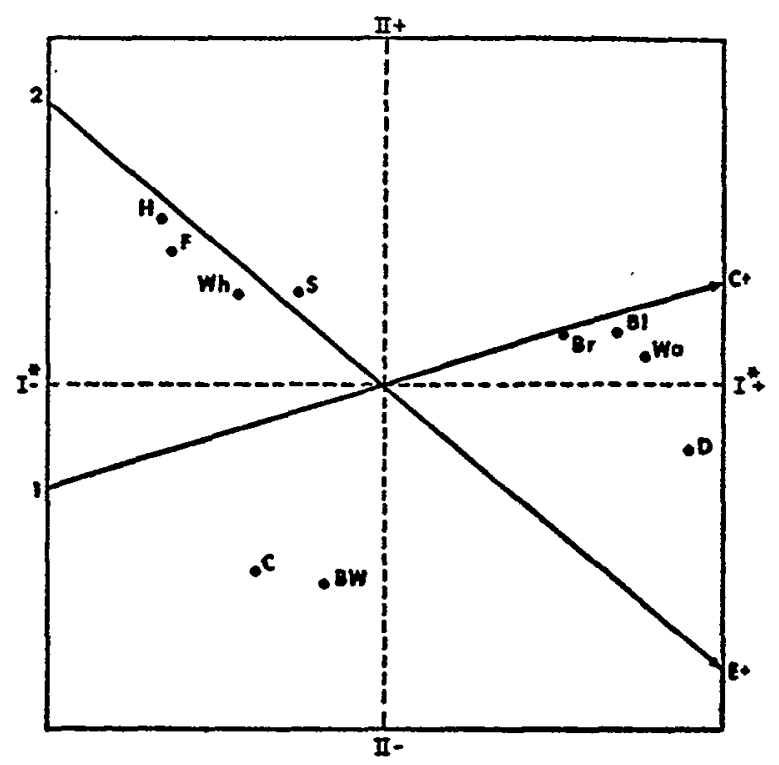

FIGURE 3B

RoTRERENCE AXES I* AND III

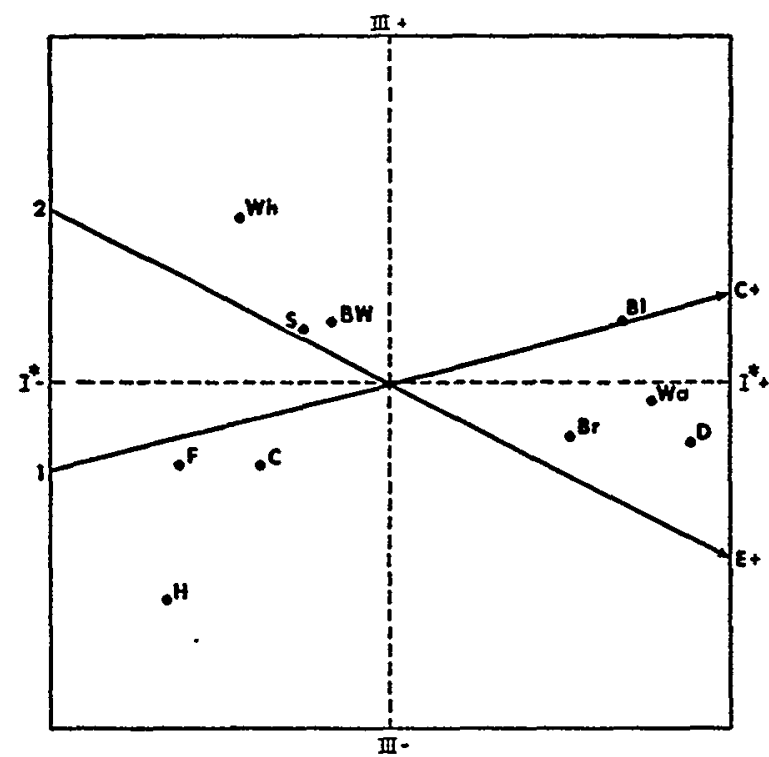

27 The direction of orthogonal factor axes extracted by the complete centroid method is arbitrary; the asterisk following the identifying number for the first axis (i.e., $\mathrm{I}^{*}$ ) signifies that the polarity of this axis was reversed to facilitate uniformity in inter-term comparisons in the larger study to which this article relates. 
FIGURE $3 \mathbf{C}$

Reprrence Axes II AND III

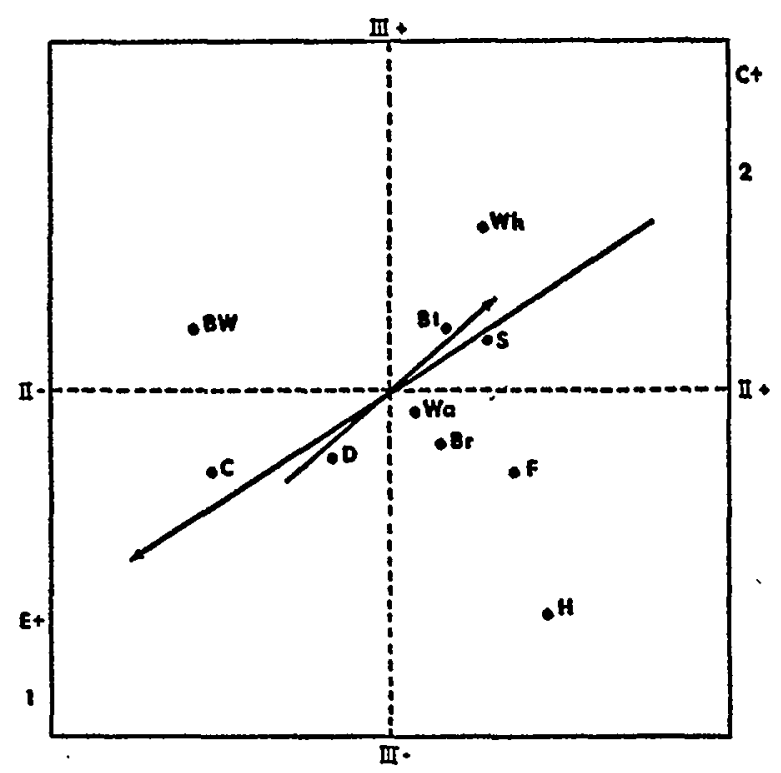

to accomplish this, are sets of weights which will determine the position of the axes in the space, and the points on each axis where the projections from the $i$-points fall. Given such data, it will then be possible to compare the rankings of the justices on the cumulative scales, with the rankings of the projections from their $i$-points on the counterpart scale axes.

It is helpful to prepare a set of two-dimensional plots of the $i$-points against the reference axes, similar to Figure 3 but without (of course) the scale axes. Initial estimates of weights can be made from an examination of such two-dimensional plots. More precise determination of a set of acceptable weights requires mathematical analysis of the factor matrix of Table $V$, and the use of a calculating machine. The distance from the origin of the factor space to the point which is closest to a given $i$-point, on any scale axis, is computed by use of the formula,

$$
d=\frac{\alpha x+{ }_{\beta} y+\gamma z}{\left(\alpha^{2}+\beta^{2}+\gamma^{2}\right)^{1 / 2}}
$$

where $d$ is the distance from the origin to the point on the scale axis where it is orthogonal to the projection from the $i$-point; $x, y$, and $z$ are coordinates of the factorial reference axes for the $i$-points; and $\alpha, \beta$, and $\gamma$ are the coefficients which determine the position of the scale axis in the three-dimensional factor space. The same set of coefficients also provides the reference axis coordinates for the positive terminus of the scale axis.

It is not assumed that the positions in which the scale axes have been placed, in 
TABLE VI

Reference Axis Coordinates, Coefficients, and Cosines for Axes

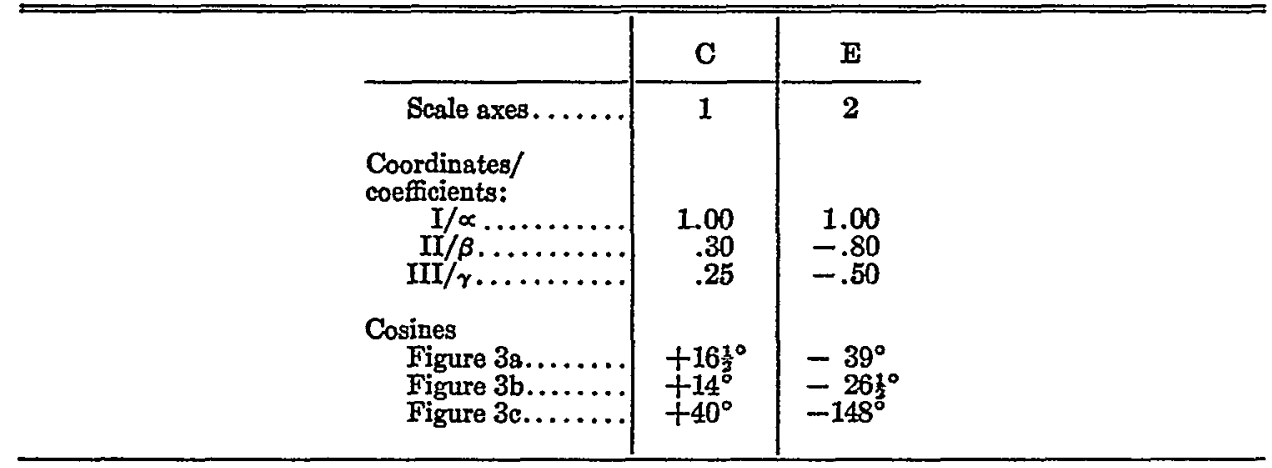

Figure 3, constitute a uniquely "best" fit to the configuration of $i$-points; but it is assumed that the positions defined in Table VI and shown in Figure 3 are an appropriate and approximately correct solution. One way to conceptualize this question is to think of a cone which intercepts a relatively quite small circular area on the surface of a unit sphere; all axes lying within the cone will array the projections from $i$-points so as to produce the same set of rankings of the justices as will be produced by any other axis within the cone.

The three plots of Figure 3 may be thought of as three views of a cube. Figure $3^{a}$ is a top view, Figure $3^{b}$ is a side view, and Figure $3^{c}$ is an end view. With relationship to reference axis $\mathrm{I}$, the $\mathrm{C}$ scale axis enters from the lower right octant of the cube, passes through the origin, and emerges at the end through the upper left octant. The $E$ scale axis passes downward and to the right of $I$. Reference axis I, it should be noted, is approximately the centroid, or arithmetic mean, of the $\mathrm{C}$ and $\mathrm{E}$ scale axes. Both the $\mathrm{C}$ and $\mathrm{E}$ scale axes are positioned almost exactly the same as for the 1960 Term.

The $\mathrm{C}$ axis clearly passes closest to Black, who also appears to have the most extreme projection on the positive segment of the axis. (Such a projection would correspond, of course, to Black's position with the highest score on the $\mathrm{C}$ cumulative scale.) Douglas, Warren, and Brennan obviously project in that sequence upon the positive segment of the $\mathrm{C}$ axis. Stewart clearly will project upon the $\mathrm{C}$ axis somewhere near but to the left of the origin, which means that his "loading" on the axis will be low and negative. And the remaining five justices will project upon the negative segment of the $C$ axis.

Douglas, Black, Warren, and Brennan all will project positively upon the $E$ axis, although we cannot be certain, from an examination of Figure 3 , whether Black will precede Brennan on the axis, as he does on the cumulative scale. Clark, who ranked fourth on the $E$ cumulative scale, clearly will project to the sixth 
position on the $\mathrm{E}$ axis, behind both Brennan and White; and the remaining justices will project negatively, corresponding to their negative scale scores for this variable.

Figure $3^{a}$ shows that in terms of the first two factors, which are the most important ones in accounting for the differences among the justices, the latter are grouped into three clusters:

(I) Douglas, Warren, Black, and Brennan, who will project positively upon both $C$ and $E$;

(2) White and Clark, who will project positively upon $\mathrm{E}$ but negatively on $\mathrm{C}$; and

(3) Stewart, Whittaker, Frankfurter, and Harlan, who will project negatively upon both $\mathrm{C}$ and $\mathrm{E}$.

\section{F. A Correlational Test of the Theory}

The principal hypothesis underlying this study is that differences in the attitudes of the justices towards the basic issues raised by the cases that the Court decides account for the differences in the voting behavior of the justices. In short, Supreme Court justices vote as they do because of their attitudes towards the public policy issues that they decide. We are now in a position to make a statistical test of this hypothesis.

The $i$-points of the justices are separated in the factor space because of variance in the extent of majority participation of individual justices; but the factor analysis routine knows absolutely nothing about the subject matter of the values to which the decisions relate. The relative degrees of support by the justices for the key substantive issues can be determined by cumulative scaling; but cumulative scaling is a unidimensional measurement device, and each such scale is based upon a different universe of content, and is quite independent methodologically (as distinguished from psychologically) from every other scale.

We shall assume, therefore, that if the cumulative scales can be reconstituted as a set of scale axes whose position is consistent with the configuration of $i$-points in the factor space, then the attitudinal differences of the justices on the cumulative scales must account for the variance in the voting behavior of the justices, which is represented by the spatial separation of their ideal-points in the multidimensional factor space. If the correspondence between the set of cumulative scales and their scale axis analogues can be established in accordance with accepted procedures of statistical proof, then we shall have proved, in a mathematical sense, that the justices of the Supreme Court vary in their voting behavior according to the differences in their attitudes towards the scale variables.

Table VII presents a comparison of the cumulative scale scores, and the distances along the counterpart scale axes at which the $i$-points project (as determined by formula 3), together with the corresponding sets of rankings, for all justices on both of the major variables. Although both scale scores and axis loadings range in value, 
TABLE VII

Correlation of Judiciar Ranks on Scales and Scale Axes

\begin{tabular}{|c|c|c|c|c|c|c|c|c|c|}
\hline \multicolumn{5}{|c|}{ C } & \multicolumn{5}{|c|}{$\mathbf{E}$} \\
\hline Axis & \multicolumn{3}{|c|}{ Ranks } & Scale & Axis & \multicolumn{3}{|c|}{ Ranks } & Seale \\
\hline $\begin{array}{r}.729 \\
.727 \\
.725 \\
.486 \\
-.136 \\
-.212 \\
-.304 \\
-.531 \\
-.560 \\
-.630\end{array}$ & $\begin{array}{r}1 \\
2 \\
3 \\
4 \\
5 \\
6 \\
7 \\
8 \\
9 \\
10\end{array}$ & $\begin{array}{l}\mathrm{Bl} \\
\mathrm{D} \\
\mathrm{Wa} \\
\mathrm{Br} \\
\mathrm{S} \\
\mathrm{Wh} \\
\mathrm{BW} \\
\mathrm{F} \\
\mathrm{C} \\
\mathrm{H}\end{array}$ & $\begin{array}{r}1 \\
2 \\
3 \\
4 \\
5 \\
7 \\
6 \\
8 \\
10 \\
9\end{array}$ & $\begin{array}{r}1.00 \\
.95 \\
.87 \\
.69 \\
. .28 \\
-.10 \\
-.18 \\
-.69 \\
-.95 \\
-.74\end{array}$ & $\begin{array}{r}.819 \\
.536 \\
.344 \\
.343 \\
.134 \\
.095 \\
-.411 \\
-.544 \\
-.592 \\
-.646\end{array}$ & $\begin{array}{r}1 \\
2 \\
3 \\
4 \\
5 \\
6 \\
7 \\
8 \\
9 \\
10\end{array}$ & $\begin{array}{l}\mathrm{D} \\
\mathrm{Wa} \\
\mathrm{Bl} \\
\mathrm{Br} \\
\mathrm{BW} \\
\mathrm{C} \\
\mathrm{S} \\
\mathrm{H} \\
\mathrm{F} \\
\mathrm{Wh}\end{array}$ & $\begin{array}{r}1 \\
2 \\
3 \\
5 \\
6 \\
4 \\
7 \\
9 \\
8 \\
10\end{array}$ & $\begin{array}{r}.82 \\
.65 \\
.59 \\
.29 \\
.15 \\
-.35 \\
-.18 \\
-.82 \\
-1.56 \\
-1.00\end{array}$ \\
\hline \multicolumn{4}{|c|}{$\begin{array}{l}\text { Rank correlation coefficient (tau) } \ldots \\
\text { Significance level, } 1 \text {-tailed (p)...... }\end{array}$} & $\begin{array}{l}.911 \\
.000015\end{array}$ & & & & & $\begin{array}{l}.867 \\
.000058\end{array}$ \\
\hline
\end{tabular}

in principle, from $+\mathrm{I}$ to $-\mathrm{I}$, so that some meaning can be attached to direct comparison of pairs of corresponding scores and loadings, it will be recalled that, for mathematical reasons relating to the marginal distributions of the fourfold tables, the intervals on the two types of continua are not genuinely commensurable. Scale scores, indeed, are directly related to the proportion of pro decisions in any set of cases.

This means that the same ranking of justices might reflect a large number of different sets of scale scores; and the variation within such sets is therefore a function not of variation in judicial attitudes but rather of the relative extremity of the stimuli (cases). Moreover, it has been determined experimentally that the error variance in the factor analysis routine is usually around ten per cent, while the error variance in the cumulative scales is only slightly less; and there are other sources of error variance implicit in the general method. Therefore, it seems reasonable to employ the nonparametric rank correlation test for the purpose of making the comparison. In spite of the seeming precision of coefficients carried to the third decimal place, it would be fatuous to pretend that the measurement employed in this study can hope to be more than a rough approximation of empirical reality.

As Table VII indicates, there are two inconsistencies in the two sets of rankings for $\mathrm{C}$, involving Whittaker and White, ${ }^{58}$ and Clark and Harlan. However, it will be observed that the probability of such close agreement between the two sets of rankings having occurred by chance is less than one chance in 66,666 . Or, in other words, if one were to plot $i$-points and scale axes on the basis of coordinates drawn from a table of random numbers, and draw a set of numbers in a similar manner for the scale scores, and then compare the two sets of rankings, one would have

s The rankings of 6 or 7 for Whittaker and White on the $C$ scale and axis demonstrate the extent to which there is homogeneity between the attitudes of White, and the justice whom he replaced, toward civil liberty issues. 
to expect to repeat these procedures at least sixty-six thousand times before one could expect to achieve such close agreement between the two sets of rankings more than once on the basis of chance alone.

The correspondence between the two sets of rankings for $E$ also is very close, and again there are two inconsistencies. Frankfurter and Harlan are reversed in order upon the axis; and although, as we already have pointed out, it seems unlikely that Frankfurter's extensive non-participation affected his scale score on $\mathrm{E}$, it is most probable that it did materially affect the location of his $i$-point, since phi coefficients based upon small cell frequencies (in the fourfold tables) will give more weight to small differences than those based upon more full participation. Therefore, our interpretation of the Frankfurter-Harlan reversal is that it is due to error variance in the configuration of $i$-points, resulting from Frankfurter's illness during the latter part of the term.

The other inconsistency involves Clark's lower ranking on the axis than on the scale. As we have explained earlier, the $E$ scale's discrimination, in ranking Clark before Brennan, appears to be valid, even though this is the first time that Clark has outranked Brennan on $E$ since they have sat together on the Courtalthough Clark did rank fourth on E during the 1954 and 1955 Terms, after Warren but before Brennan had joined the Court. We also have pointed out that White's non-participation was so extensive that the E Scale might be in error ranking White below Clark and Brennan. This possible error readily explains the Clark-White reversal in rankings. We are left with Clark-Brennan, and our conclusion is that the $i$-point configuration is in error with regard to Clark's position in the space. Although Clark has the second highest negative loading on the third factor, it would have to be much more negative than it is, in order for Clark to project consistently upon the $\mathrm{E}$ scale axis.

The possibility of chance replication of the pair of rankings observed to obtain for $E$ is so small-about one chance in 20,000-that the most reasonable inference is that these rankings are functions of the same underlying cause: the attitudes of the justices towards the economic policy issues raised for decision in the set of $\mathbf{E}$ scale cases. Indeed, the correlation between both sets of rankings is very high, with or without the above explanations, since no reasonable person expects to discover perfect consistency in the exercise of human judgment, even on the part of professional judges.

From a statistical point of view, it should be noted that the probabilities shown in Table VII relate to the probability of producing, by chance alone, the indicated congruence between any one scale and the point configuration. The prospect of chance replication of as good a fit for both scales simultaneously, with the same fixed point configuration, is of course very much more remote; indeed, the joint probability, which is the product of the two discrete probabilities, is a truly astronomical number: $.0^{9} 87$, or approximately one chance in a billion. It seems warranted, under these circumstances, to reject the null hypothesis, and to accept instead the hypothesis that 
the variance in the voting behavior of the justices during the I96r Term can be adequately accounted for by the differences in their attitudes towards the fundamental issues of civil liberty and economic liberalism.

\section{G. The Psychological Distance Separating the Justices}

Now that we have established a basis for confidence in the proposition that the judicial ideal-points in the factor space do indeed function as reasonably adequate symbolizations of the respective attitude syndromes of the individual justices, there remains one final question that we can examine. Discussion about the justices frequently revolves around such questions as which ones tend to share the "same point of view," and which ones are "farthest apart" in their thinking. The factor space provides a convenient vehicle for objective measurement of the psychological distance which separates each justice from each of the others.

Since the measurement of these psychological distances is purely mathematical, we shall carry it out in five-dimensional space, which will afford what may be a slightly more accurate basis for measurement than the three-dimensional space depicted in Figure 3, since the fourth and fifth factors will permit us to consider the effect of other dimensions which-assuming that we are not merely interjecting the distortion of error variance-would have to be considered to be a part of the attitude syndrome of each justice. The psychological distance will be measured on the same scale as that employed for the three-dimensional factor space: along orthogonal reference axes, each of which extends from $+\mathrm{I}$ to $-\mathrm{I}$. The standard formula for computing the distance between any two points in orthogonal fivespace is:

(4)

$$
d_{i 1-i 2}=\left[\left(v_{1}-v_{2}\right)^{2}+\left(w_{1}-w_{2}\right)^{2}+\left(x_{1}-x_{2}\right)^{2}+\left(y_{1}-y_{2}\right)^{2}+\left(z_{1}-z_{2}\right)^{2}\right]^{1 / 2}
$$

where $\mathrm{d}$ is the distance, $i_{1}$ and $i_{2}$ are the ideal-points of a pair of justices, and $v, w, x$, $y$, and $z$ are the coordinates (or "loadings") of the justices on factors I-V.

The results of computations based upon the use of this formula are shown in Table VIII. Black and Warren are the closest two justices, in terms of their attitudes towards the policy issues that the Court decided in the I96I Term; they are separated by a distance of only 30 in the five-dimensional factor space, although Brennan, too, is only .32 away from Warren. Black and Brennan, at -47 , are the next closest pair, so that the triad of Black-Warren-Brennan constitutes the set of three justices whose attitudes were most similar toward the issues confronting the Court during the 196r Term. The common misapprehension that Douglas and Black are the two justices who "are closest together in their thinking" is contradicted by Table VIII, just as it failed to find support in equivalent data for the 1960 Term. There are, indeed, no less than eight closer pairs than Douglas-Black; and both Douglas and Black are closer to Warren and to Brennan than they are to each other. However, it is true that the closest group of four justices consists of the Black-Warren-Brennan triad, plus Douglas. 
TABLE VIII

Attitudinat Distances Among Judicial Ideaz-Points, I96i Term

\begin{tabular}{|c|c|c|c|c|c|c|c|c|c|c|}
\hline & $D$ & $\mathrm{BI}$ & $\mathrm{Wa}$ & $\mathrm{B}_{\mathrm{T}}$ & $\mathbf{S}$ & $\mathrm{BW}$ & C & Wh & $F$ & H \\
\hline 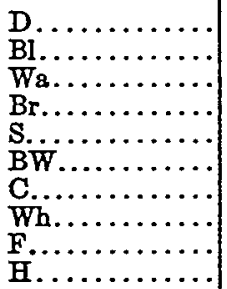 & $\begin{array}{l}\overline{.78} \\
.64 \\
.77 \\
1.29 \\
1.45 \\
1.54 \\
1.55 \\
1.69 \\
1.82\end{array}$ & $\begin{array}{l}.78 \\
.30 \\
.47 \\
.99 \\
1.19 \\
1.40 \\
1.39 \\
1.42 \\
1.74\end{array}$ & $\begin{array}{l}.64 \\
.30 \\
. .32 \\
1.10 \\
1.22 \\
1.35 \\
1.49 \\
1.48 \\
1.68\end{array}$ & $\begin{array}{l}.77 \\
.47 \\
.32 \\
.91 \\
1.10 \\
1.14 \\
1.26 \\
1.27 \\
1.38\end{array}$ & $\begin{array}{r}1.29 \\
.99 \\
1.10 \\
.91 \\
1.00 \\
1.03 \\
.75 \\
.57 \\
1.03\end{array}$ & $\begin{array}{l}1.45 \\
1.19 \\
1.22 \\
1.10 \\
1.00 \\
\overline{.51} \\
1.24 \\
1.24 \\
1.58\end{array}$ & $\begin{array}{l}1.54 \\
1.40 \\
1.35 \\
1.14 \\
1.03 \\
.51 \\
\frac{1.24}{1.24} \\
1.24\end{array}$ & $\begin{array}{l}1.55 \\
1.39 \\
1.49 \\
1.26 \\
.75 \\
1.24 \\
1.24 \\
1.16 \\
1.16\end{array}$ & $\begin{array}{l}1.69 \\
1.42 \\
1.48 \\
1.27 \\
.57 \\
1.24 \\
1.13 \\
1.16 \\
.87\end{array}$ & $\begin{array}{l}1.82 \\
1.74 \\
1.68 \\
1.38 \\
1.03 \\
1.58 \\
1.24 \\
1.16 \\
.87 \\
\end{array}$ \\
\hline
\end{tabular}

The most notable of the remaining affinity relationships are the $.5 \mathrm{r}$ for the WhiteClark pair; and Stewart's .57 separation from Frankfurter and .75 from Whittaker, plus the Frankfurter-Harlan distance of .87 . It is apparent, however, that there are no triads, or larger groupings, among these remaining six justices, which do not involve substantial separation between some of the included pairs. The most general statement that can be made is that three general points of view may be identified:

I. The liberal attitude, characteristic of the relatively closely grouped quadruple, of whom Warren was the most typical representative, at a minimal average distance of .42 from his colleagues Brennan, Black, and Douglas.

II. The idiosyncratic attitude, characteristic of the Clark-White pair, who are relatively close to each other, and relatively widely separated from all of the other justices, as an examination of the three-dimensional space depicted in Figure 3 makes evident.

III. The conservative attitude, characteristic of the remaining four justices, and best typified by Stewart, whose average distance from Whittaker, Frankfurter, and Harlan, was .78-a measure which suggests that the conservatives were roughly twice as far apart from each other, in their attitudes in general, as were the liberals.

The greatest difference in attitude is that between Douglas and Harlan, who are maximally separated at a distance of r.82. Harlan is also the justice who is most different from Black, Warren, Brennan, and White, while it is Douglas whose attitude is most dissimilar from Whittaker, Frankfurter, Clark, and Stewart, as well as from Harlan.

If we seek an "average" justice whose point of view best typifies that of the Court as a whole, there are two possibilities: Brennan, whose average distance from all of his colleagues is .96; and Stewart, whose average distance also is .96. However, the range of the distances separating Stewart from the rest of the Court is .7r, considerably less than Brennan's range of r.o6. When we take 
both the mean and the range of the psychological distances into account, Stewart thus clearly emerges as the most typical member of the Court, a position that he also occupied in the 1960 Term. Such a finding is not inconsistent, of course, with the findings of scale analysis, and it accords with the configuration shown in the three-dimensional space of Figure 3. The most atypical justice during the I96I Term was Harlan who, separated by an average distance of $\mathrm{r} .39$ from his colleagues, entertained the most generally extreme views of any of the justices.

Table VIII also permits us to make a direct inference concerning a question which, in the past, there has been a tendency to approach by a variety of indirect routes. To what extent do the views of Byron White replicate those of Charles Whittaker, the man to whose position on the Court he succeeded? Not very closely, according to these data. Their separation of $\mathrm{I.24}$ is greater than the mean, for all pairs, of x.I5; and White and Whittaker are no closer together than either of them is, on the average, to the rest of his colleagues. This finding is to some extent qualified and explained by the $\mathrm{C}$ and $\mathrm{E}$ scales, which show that White and Whittaker both were rather neutral toward civil liberty issues, but that White was considerably more liberal in his attitude toward economic policy than was Whittaker, who concluded his services on the Court, in perfect accord with his position in other recent terms, as the anchor man on the $\mathrm{E}$ scale.

\section{IV}

\section{PRedictions for the Ig62 TERM}

Instead of closing this paper with a summary of the findings, we shall employ them as the basis for a set of predictions about the 1962 Term of the Supreme Court, thus returning to the more fundamental questions about the study of judicial behavior with which we began this discussion. We shall also take into consideration the equivalent findings that have been published for the I960 Term, and other summary data for recent terms that have been reported in this paper. Freshman Justice Arthur Goldberg presents a special problem, of course, because we have no information about him on the basis of the data examined thus far, since he joined the Court at the beginning of the 1962 Term. However, rather than to avoid the problem by limiting our predictions to the other eight justices, we shall make certain assumptions about his probable behavior, on the basis of what is a matter of public record concerning his socioeconomic and political background characteristics and his previous legal career. On the basis of other recently published research that has correlated such background characteristics with judicial decision-making behaviors, ${ }^{59}$ we shall extrapolate for Justice Goldberg and make our predictions for a full Court.

\footnotetext{
Nagel, Testing Relations between Judicial Characteristics and ludicial Decision-Making, I5 Western PoL. Q. 425 (1962); Nagel, Ethnic Affliations and Judicial Propensities, 24 J. Pourtics 92 (1962); and Nagel, Political Party Affiliation and Judges' Decisions, 55 AM. PoL. Scr. Rev. 843 (I96r); Schmidhauser, The lustices of the Supreme Court: $A$ Collective Portrait, 3 Mrdwest J. Politucal Science I (1957), and Schmidhauser, Stare Decisis, Dissent, and the Background of the Justices of the Supreme Court of the United States, I4 U. Toronto L.J. I94 (I962).
} 


\section{A. The Universe of Raw Data}

r. The total of cases decided on the merits will be $x 70 \pm 05$ per cent.

2. A majority of the total cases decided on the merits will be split decisions.

3. The proportion of cases decided formally (i.e., after oral argument, and with a signed opinion for the Court) in relation to the total of cases decided on the merits (formal plus per curiam) will be approximately two-thirds, or more precisely, sixtyseventy per cent.

\section{B. Rankings of the Justices}

In a recent article, Professor S. Sidney Ulmer ventured the prediction that, for the C scale, "the rank order for the Ig6r term (October, Ig6I-June, I962) will be relatively close to that derived for the 1960 term." 100 He also thought that changes in the personnel of the Court might adversely affect the degree of correlation. In fact, the rank correlation between the $\mathrm{C}$ scale that we have previously reported for the $1960 \mathrm{Term}$, and Figure $\mathrm{I}$ of this paper, is: tau $=+.930$, at a confidence level of less than .00012; the correlation between the $\mathrm{C}$ scale that Ulmer reported for the I 960 Term, and Figure $I$ of this paper, is: tau $=+.778$, at a confidence level of .0012. There are, it is evident, minor differences between Ulmer's C Scale for the 1960 Term, and our own: these differences involve the order of Whittaker, Frankfurter, and Harlan, although both scales are in perfect agreement concerning the ranks of the other six justices, and they are also agreed that the three justices in dispute occupy ranks 6-8 on the scale.

What significantly distinguishes such disagreement from argument that takes place on a more subjective or intuitional level is that any interested reader is in a position to compare these two published $\mathrm{C}$ scales for the 1960 Term, go back to the raw data to the extent necessary, examine the minor differences in format and technique that are apparent, and form an independent and objective judgment on the question of what errors have been made by either or by both analysts. We are extremely confident that a panel of scholars, skilled in both the substantive content (viz., "the law") and the method of cumulative scaling, quickly could agree upon the most valid $\mathrm{C}$ scale for the term-and that this "best" scale would not deviate more, from either Ulmer's scale or our own, than these latter deviate from each other at present.

It does seem desirable, however, to formulate our predictions for the 1962 Term in terms of a more explicit criterion of closeness of fit than the verbal one that they shall be "relatively close." Since we generally have accepted a five per cent margin of error as constituting a reasonable criterion for other relationships that we have examined in this paper, we shall posit the same margin for present purposes; and on a scale that ranges from $+I$ to $-I$, this means that our predicted rank correlation must be not less than +.900 .

\footnotetext{
${ }^{\circ 0}$ Ulmer, A Note on Attitudinal Consistency in the United States Supreme Court, 22 Indun J. Por. Scr. 395,204 (196r).
} 
There were, of course, no personnel changes on the Court during the 1960 Term, but there were, in effect, three such changes during the Ig6I Term: Whittaker's retirement de jure, Frankfurter's retirement de facto, and White's appointment to the Court late in the term. No doubt, Professor Ulmer would be in a position to invoke his caveat about the depressing effect of personnel changes upon the stability of rankings, and explain an observed correlation of less than +.900 for the $\mathrm{C}$ scales of the $\mathrm{I} 960$ and $\mathrm{x} 96 \mathrm{I}$ terms upon that basis.

Moreover, in comparing the r $96 \mathrm{I}$ and 1962 Terms, we are faced not only with the three changes in the 1960 Term, but in addition, we now have Justice Goldberg as a new member of the Court, plus whatever other changes that may take place between the time of this writing (November, Ig62) and the end of the term in June, 1963. Nevertheless, we are prepared to make our predictions of rank order in terms of the stated criterion of acceptability. Our assumption, which we believe to be consistent with the psychological theory and model of the Court's decision-making that we have presented, is that whatever impact personnel changes may have upon the proportions of $\mathrm{C}+$ and $\mathrm{E}+$ decisions made by the Court, they should not have such a drastic effect upon individual attitudes as to result in many transpositions of ranks.

The basis for our extrapolation of a rank position for Mr. Justice Goldberg is the following set of data, which were widely disseminated by the mass news media at the time of his nomination to replace Frankfurter late in August, Ig62. Justice Goldberg rose from most humble origins, as the son of Russian immigrants, to a position at the top of his profession as a lawyer. $\mathrm{He}$ is a Jew, and thus a member of a minority religious group. He graduated as an honor student from a prominent law school (Northwestern). His professional career was primarily as counsel for labor unions; and he has had no previous judicial experience. He is a Northern Democrat, and held high political office in the Kennedy Administration as Secretary of Labor, at the time of his appointment.

These are the characteristics which are most closely associated with the liberal intellectual wing of the Democratic Party in the United States, and we should anticipate that a person who embodies them will be a liberal on issues of both civil liberty and of economic policy. Although we are aware that some justices have assumed positions, during their freshman year on the Court, that subsequently proved to be atypical for them-Warren, for example, ranked fifth on $C$, although he immediately assumed his normal rank of third on E, during the I954 Term-we shall predict for Goldberg what seems most likely, on the basis of this pre-appointment data, to become his stable rank position vis-à-vis his present set of colleagues. We can thus make the following further predictions:

4. The rank order of the justices, on the $C$ scale and the $C$ axis, the $E$ scale and the $\mathrm{E}$ axis, and the first centroid factor (I) will be as shown in Table IX; and the rank correlation that obtains empirically for any of these scales, with those predicted in Table IX, will be not less than +.900. 
TABLE IX

Predictions of the Rank Order of the Justices During the yg62 Term on Scalis of Civil Liberties, Economic Liberalism, and GeNeral Liberalism

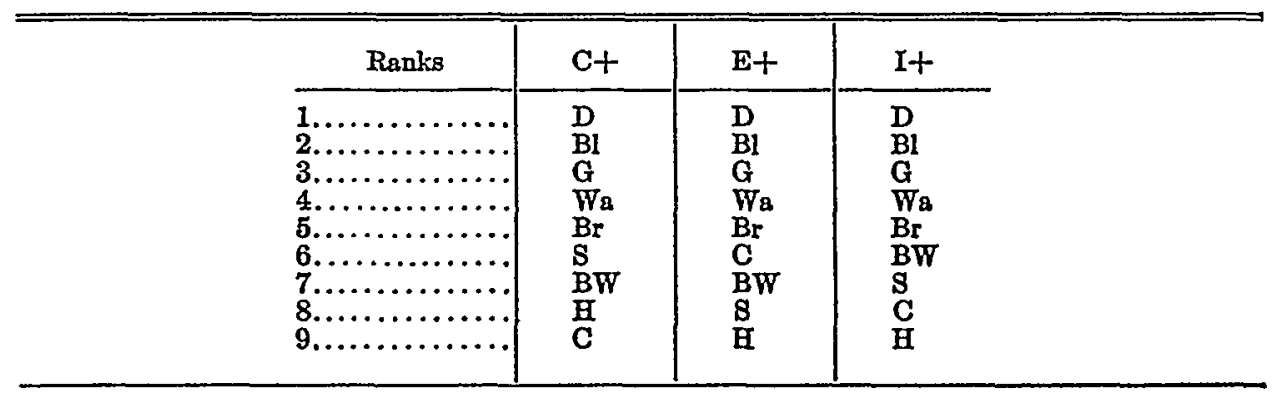

5. The loadings (or correlations) of the justices occupying the first five ranks on the first factor of general liberalism (as predicted in Table IX) will be positive, and the loadings of the remaining four justices will be negative.

\section{Proportions of Liberal Decisions}

6. At least two-thirds of the cases on the $\mathrm{C}$ scale, and also at least two-thirds of the cases on the $\mathrm{E}$ scale, will be pro-liberal decisions.

7. The division between pro and con decisions, on both the $\mathrm{C}$ scale and the $E$ scale, will coincide (within a margin of error of $\pm_{5}$ per cent of the cases on the scale) with the scale score of the median justice; and, if there are no further personnel changes on the Court during the term, this will be Brennan on each scale.

\section{Judicial Ideal-Points and Scale Axes in the Factor Space}

8. The configuration of $i$-points in the three-dimensional factor space will cluster in three distinct groups: (I) Douglas, Black, Goldberg, Warren, Brennan; (2) White, Clark; (3) Stewart, Harlan.

9. The positive half of the $C$ scale axis will transect the upper left octant, and the positive half of the $E$ scale axis will transect the lower right octant, of the factor space; and both scale axes will have correlations of $+\mathrm{r} .00$ with the first factor reference axis (It).

\section{E. The Reapportionment Cases}

It is anticipated that during the Ig62 Term, the Court will announce its decision on the merits in regard to several cases challenging state legislative reapportionment. Some of these cases already have been docketed, and others may be docketed and decided during the course of the term. We recognize that there are many specific differences among the state constitutional provisions, the facts and formulae for legislative districting, and the consequences for the two-party system, presented by the cases coming to the Court from different states. Probably the Michigan case, 
Beadle $\nu$. Scholle, ${ }^{61}$ presents the most extreme libertarian claim for the extension of the equal protection clause of the fourteenth amendment to require representation by population of both houses of the state legislature, notwithstanding a recentlyadopted state constitutional amendment and a pending referendum on a new state constitution, both of which are to the contrary.

Nevertheless, the assumption that one would have to make, on the basis of the theory discussed in this paper, is that the justices will vote in the decision of these reapportionment cases in response to their fundamental attitudes toward civil liberty, and more particularly, to that component of the $\mathrm{C}$ scale-the political equality subvariable-to which the reapportionment issue is most directly related. There have been too few cases, in recent terms, to make possible independent scaling of the political equality subvariable. But our assumption is that it lies, as a scale axis, midway between the $\mathrm{C}$ and $\mathrm{E}$ axes in Figure 3, since legislative reapportionment has such obviously important implications for public policy-making affecting economic as well as political rights and interests.

On the basis of that assumption, together with the predictions that we already have made (in Table IX) concerning judicial rankings during the term, we shall predict that:

I0. In its decision in Beadle v. Scholle, the Court will either deny certiorari to the decision of the Michigan Supreme Court in Scholle v. Hare, ${ }^{62}$ or else affirm it on the merits by a division of 5-4, with Douglas, Black, Goldberg, Warren, and Brennan voting in the majority, and the remaining justices in dissent.

II. The Court will not reverse any of the pro-reapportionment decisions of lower courts in states other than Michigan, ${ }^{63}$ nor will it affirm any of the anti-reapportionment decisions of lower courts presently docketed. ${ }^{64}$

12. Since none of the other cases presently docketed raise a more extreme claim of entitlement to political equality than does Beadle $v$. Scholle, and several of them raise claims that are less extreme, the voting divisions of the Court in those cases that are decided on the merits will range from 5-4 to 8-I; Douglas, Black, Goldberg, Warren, and Brennan will be in the majority, and Harlan will dissent, while the remaining three justices who join the majority will do so in the sequence: White, Clark, Stewart.

${ }^{01}$ No. 517, 3 I U.S.L. WEEK 3139 (U.S. Oct. 23, 1962) (docketed Oct. 15, 1962) [Mich.].

82 367 Mich. 176 , II 6 N.W.2d 350 (1962).

as Gray v. Sanders, No. II2, 3I U.S.L. WEER 3012 (U.S. July 3, 1962) (probable jurisdiction noted, 370 U.S. 921 (June 18, I962)) [Ga.]; Reynolds v. Sims, No. 508, 3 I U.S.L. WeEK $3 \times 47$ (U.S. Oct. 30, 1962) (docketed Oct. 12, 1962) [Ala.]; Price v. Christian, No. 539, 31 U.S.L. WEEK 3157 (U.S. Nov. 6, 1962) (docketed Oct. 19, 1962) [Okla.]. The first two cases are appeals from federal district courts; the third is on certiorari to the Oklahoma Supreme Court.

At W.M.C.A. v. Simon, No. 460 , 3 I U.S.L. WEEK 3103 (U.S. Oct. 2, 1962) (docketed September 26, 1962) [N.Y.]; Wesberry v. Vandiver, No. 507, 31 U.S.L. WEEK 3147 (U.S. Oct. 30, 1962) (docketed Oct. 12, 1962) [Ga.]; Vann v. Frink, No. 540, 31 U.S.L. WEEK 3157 (U.S. Nov. 6, 1962) (docketed Oct. 19, 1962) [Ala.]; Maryland Committee for Fair Representation v. Tawes, No. 554, 31 U.S.L. WEEK 3146 (U.S. Oct. 30, 1962) (docketed Oct. 24, 1962) [Md.]. The first three of these cases are appeals from federal district courts; the fourth is an appeal from the Maryland Court of Appeals. 


\section{Conclusion}

In conclusion, it should be understood that it will indeed be remarkable if all of the predictions stated above can be validated, in the decision-making behavior of the justices as observed and measured and reported by some other analyst or analysts using the theory and methods of analysis that have been explained in this paper. It will be even more remarkable if most of these predictions cannot be validated, or if any of them prove to be extremely wide of the mark. The predictions relate to the kinds of continuities in judicial behavior which, although here confined to the empirical data for a single appellate court that hardly is a typical one, can nevertheless be expected to exist in other appellate courts as well. It should thus be possible to extend the scope of inquiries along the lines described above in order to increase our systematic knowledge about courts and judges in general. To be of maximal significance, such systematic knowledge about judicial behavior will be, of course, not empirical knowledge but theoretical knowledge. ${ }^{65}$

os This is the distinction which, more than any other, separates the skilled practitioner, the "legal expert" of whom we wrote earlier in this paper, from the behavioralist. The sophisticated lawman, in the tradition of legal realism, predicts on the basis of his specialized empirical knowledge; while the behavioralist, in the tradition of modern science, predicts on the basis of his theoretical knowledge. 